\title{
Variance Swaps, Non-normality and Macroeconomic and Financial Risks
}

\author{
Belén Nieto \\ University of Alicante, Spain \\ Alfonso Novales \\ University Complutense, Spain \\ Gonzalo Rubio \\ University CEU Cardenal Herrera, Spain
}

This version: September 2013

Keywords: variance risk premium, non-normality, economic risks, hedging.

JEL classification: C13, C14, G10, G12

The authors acknowledge financial support from the Ministry of Science and Innovation through grant ECO2011-29751 [Belén Nieto (belen.nieto@ua.es)], and from the Ministry of Economics and Competitiveness through grants ECO2012-31941 [Alfonso Novales (anovales@ccee.ucm.es)] and ECO2012-34268 [Gonzalo Rubio (gonzalo.rubio@uch.ceu.es)]. The authors also acknowledge financial support from Generalitat Valenciana grant PROMETEOII/2013/015. They thank seminar participants at the University CEU Cardenal Herrera, University Jaume I of Castellón, University of Zaragoza, the $33^{\text {th }}$ Meeting of the European Accounting Association, the $8^{\text {th }}$ INFINITI Conference on International Finance, and the XVII Foro de Finanzas, IESE. We are especially grateful for the constructive and helpful comments of Juan Ángel Lafuente and Enrique Sentana, the editor, and two anonymous referees that substantially improved the contents of the paper. We assume full responsibility for any remaining errors. 


\title{
Variance Swaps, Non-normality and Macroeconomic and Financial Risks
}

\begin{abstract}
This paper studies the determinants of the variance risk premium and discusses the hedging possibilities offered by variance swaps. We start by showing that the variance risk premium responds to changes in higher order moments of the distribution of market returns. But the uncertainty that determines the variance risk premium -the fear by investors to deviations from Normality in returns- is also strongly related to a variety of macroeconomic and financial risks associated with default, employment growth, consumption growth, stock market and market illiquidity risks. We conclude that the variance risk premium reflects the market willingness to pay for hedging against these financial and macroeconomic sources of risk. An out-of-sample asset allocation exercise shows that the inclusion of the variance swap reduces the modified Value-at-Risk with respect to a portfolio holding exclusively the equity market portfolio.
\end{abstract}




\section{Introduction}

Why is the variance risk premium ( $V R P$ hereafter) reported to be negative, on average, for all available horizons? Since the payoff of a variance swap contract is the difference between the realized variance and the variance swap rate, negative returns to long positions on variance swap contracts for all time horizons mean that investors are willing to accept negative returns for purchasing realized variance. ${ }^{1}$ Equivalently, investors who are sellers of variance and are providing insurance to the market, require substantial positive returns. This may be rational, since the correlation between volatility shocks and market returns is known to be strongly negative and investors want protection against stock market crashes. However, this intuition does not explain the large average negative variance risk premium observed at all horizons. In order to be more precise about our understanding of the negative magnitude of the variance risk premium, this paper identifies the main aggregate risks that variance swaps may hedge.

We formally investigate the hedging ability of variance swaps against a variety of financial and macroeconomic risks. The first contribution of this paper is to show that going long in a variance swap allows the investor to hedge not only equity market risk, but also default risk, aggregate consumption risk, and market-wide illiquidity risk. Additionally, this hedging ability depends on the investment horizon. It is important to notice that our objective is not to perform a horse race among available instruments to check whether the variance swap is more effective in covering business cycle and financial risks than potential competitors. Specifically, we do not compare the variance

\footnotetext{
${ }^{1}$ In this paper, we analyze the variance swap contract on the S\&P500, and not stock variance swaps on individual assets. A variance swap is an OTC derivative contract in which two parties agree to buy or sell the realized volatility of an index or single stock on a future date. Whenever we mention a variance swap or a variance risk premium, we refer to just variance swaps on the equity market portfolio. For empirical evidence about the negative variance risk premium on the S\&P500 index, see Carr and Wu (2009) and the papers cited in their work.
} 
swap with default-based derivatives, individual variance swaps or with VIX call and put options. These alternative instruments may be playing a similar role than variance swaps. This paper focuses on analyzing the risks that the variance swaps actually hedge in order to understand better the large negative variance risk premium reported in literature.

The aim of the second part of the paper is to understand why variance swaps are able to hedge risks embedded in variables other than equity market returns. For this purpose we follow the model proposed by Chabi-Yo (2012) that theoretically determines the variance risk premium in terms of higher order moments of the conditional return distribution over and above the mean and variance of the stock market portfolio. Our estimates of that model indicate that, for maturities up to 6 months, the VRP is mainly determined by kurtosis. For the 12-month horizon, investors also fear that skewness contributes to the distance between the physical and risk-neutral volatilities. In addition, we also analyze the relation between these higher moments of equity returns and standard macroeconomic and financial variables measuring aggregate risks. Our results suggest that kurtosis, characterizing the market portfolio return, is positively and significantly related to the time-series behaviour of the dividend-price ratio, default risk, aggregate consumption growth, and market-wide illiquidity risk. This finding may explain the ability of the variance swap for hedging the risk associated to these financial and macroeconomic risk factors. Additionally, the capacity of the variance swap for hedging against market risk at all horizons, the price-dividend risk at the one-month horizon, and default risk at the 6-month horizon may also be associated with the relation between these variables and the skewness of returns. 
Since our analysis suggests that variance swaps may be effective in covering the risk of extreme bust events in returns, we finally investigate the benefits of adding to the equity market portfolio a long position in the variance swap. We find that the modified Value-at-Risk of the portfolio decreases due to the inclusion of the volatility exposure.

This paper is organized as follows. Section 2 briefly describes the variance swap contract and defines the variance risk premium, while Section 3 contains a description of the data. The hedging ability of the variance risk premium against a variety of financial and economic risks is reported in Section 4. The determinants of the variance risk premium and their relationship to several financial and economic risks are discussed in Section 5. Section 6 provides two robustness tests. The first one considers estimating realized variance using daily returns, rather than intra-daily returns. The second one employs an extended sample period. Section 7 analyzes the benefits of including an exposure to variance into an equity portfolio and, finally, Section 8 concludes with a summary of our findings.

\section{Variance Swap Contracts and the Variance Risk Premium}

A variance swap is an over-the-counter financial instrument that pays the difference between a standard estimate of the realized variance of the return on a given asset and the fixed variance swap rate. One leg of the variance swap pays an amount based upon the realized variance of daily log returns over the life of the contract, $R V_{t, t+\tau}$, computed with the commonly used closing price of the underlying asset. The other leg of the swap pays a fixed amount, the strike or variance swap rate, $S W_{t, t+\tau}$, quoted at the deal's inception. Thus the net payoff to the counterparties is the difference between these two values. It is settled in cash at the expiration of the deal, though some cash payments are 
likely to be made along the way by one or the other counterparty to maintain an agreed upon margin. The payoff of a variance swap with maturity at $t+\tau$ is therefore given by,

$$
N_{\text {var }}\left(R V_{t, t+\tau}-S W_{t, t+\tau}\right)
$$

where $N_{v a r}$ denotes variance notional.

Since variance swaps cost zero at entry, for no arbitrage opportunities to exist the variance swap rate must be equal to the risk-neutral expected value of the realized variance,

$$
S W_{t, t+\tau}=E_{t}^{Q}\left(R V_{t, t+\tau}\right)
$$

where $E_{t}^{Q}($.$) is the time- t$ conditional expectation operator under some risk-neutral measure $Q$. The variance risk premium at period $t$ is then defined as,

$$
V R P_{t, t+\tau}=E_{t}^{P}\left(R V_{t, t+\tau}\right)-S W_{t, t+\tau}
$$

where $E_{t}^{P}($.$) is the time- t$ conditional expectation operator under the physical probability measure $P$. If investors price variance risk, the variance swap rate will differ from the expected realized variance under $P$ at the corresponding horizon, the difference being the variance risk premium.

\section{Data and Descriptive Statistics}

In this paper we analyze variance swap contracts on the S\&P 500 index for five alternative horizons: $\tau=1,2,3,6$, and 12 months. The midpoint of bid and ask quotes at the closing of the day for variance swap rates from January 4, 1996 to January 31, 
2007 were obtained from the Bank of America. ${ }^{2}$ We get monthly data by using the midquotes on the last day of each month. ${ }^{3}$

Our estimation of realized variance uses intra-daily returns on the S\&P 500 index observed at 30-minute intervals, from 9 a.m. to 3 p.m. ${ }^{4}$, Central Standard Time zone, with data provided by the Institute of Financial Markets. For each month $t$ in our sample, we compute the realized variance for each maturity $\tau$ of a variance swap contract ( $\tau=1,2,3,6$, and 12 months). Let $R_{t+j}$ be the S\&P500 log-return over the 30minute interval between $t+j-1$ and $t+j$, and let $N^{\tau}$ be the number of 30-minute periods in the interval $(t, t+\tau) .^{5}$ Then, realized variance from $t$ to $t+\tau$ is estimated as:

$$
R V_{t, t+\tau}=\frac{1}{\tau} \sum_{j=1}^{N^{\tau}}\left(R_{t+j}-\bar{R}_{N^{\tau}}\right)^{2}
$$

where $\bar{R}_{N^{\tau}}$ is the average return over the 30-minute periods in the interval from $t$ to $t+\tau$. By dividing the sum of squared deviations by $\tau$, the realized variance is given on a monthly basis independently of the horizon.

For each month $t$ and each maturity $\tau$, we estimate the variance risk premium, $V R P$, as the difference between the realized variance and the swap rate,

$$
V R P_{t, t+\tau}=R V_{t, t+\tau}-S W_{t, t+\tau}
$$

\footnotetext{
2 The availability of these data allows us to avoid the relatively complex calculations and large datasets needed to replicate the swap rates using calls and puts on the S\&P500 index. See, among others, Carr and $\mathrm{Wu}$ (2009) for details of the estimation.

${ }^{3}$ It is usually accepted that the mid-quote is a good representative proxy of the fundamental value of the asset, which explains why is widely employed in literature. Regarding the transformation of the variance swap rates from daily data to a monthly frequency sample, we also consider the average rate over all days within each month. It turns out that the characteristics of both series are practically the same.

4 There is a relatively large literature covering the high-frequency variance computation. A recent example discussing the estimation of the variance risk premium using high-frequency techniques is the paper by Bollerslev et al. (2010).

${ }^{5}$ Depending on the specific month and horizon, $N^{\tau}$ takes different values. On average, $N^{\tau}$ is 270 for $\tau=1$ and 3244 for $\tau=12$.
} 
Clearly, the variance risk premium is only known at time $t+\tau$, since the realized variance is only observed at the end of the swap contract.

Figure 1 displays variance swap rates and realized variances for 1-, 3- and 6month maturities. As expected, the swap rate is most often above the level of realized variance, especially for longer maturities. This evidence is similar to that shown by Carr and $\mathrm{Wu}$ (2009) for stock market indices and, to a lesser extent, for individual stocks. ${ }^{6}$ It is clear that investors are willing to accept a significantly negative return to long variance swaps on the S\&P index in exchange for being hedged against future unexpected volatility shocks. Therefore, shorting variance swap contracts in the S\&P index generates positive average excess returns during our sample period, since the variance risk premium can be seen as the return on holding the variance swap contract. Panel A of Table 1 reports descriptive statistics of the $V R P$ calculated from equation (5) for alternative maturities. The variance risk premium is always negative on average, and it becomes more negative with maturity. Panel $\mathrm{B}$ of Table 1 reports the correlation coefficients between the variance risk premia at any two different maturities. The correlation between variance risk premia at adjacent maturities is high, but it weakens for distant maturities. This suggests the existence of more than one factor explaining the term structure of the variance risk premium. ${ }^{7}$

We obtain nominal consumption expenditures on nondurable goods and services from NIPA Table 2.8.5. Population data is taken from NIPA Table 2.6, and the price deflator is computed using prices from NIPA Table 2.8.4 with basis on year 2000. All

\footnotetext{
${ }^{6}$ Driessen et al. (2009) and Vilkov (2008) show that the variance risk premium for stock indices is systematically larger, i.e., more negative, than for individual securities. They argue that the variance risk premium can in fact be interpreted as the price of time-varying correlation risk.

${ }^{7}$ This is consistent with the formal analysis contained in Egloff et al. (2010) and Amengual (2009). They show that two factors are needed to capture the term structure variation of the variance swap rates. The first factor controls the instantaneous variance rate variation, while the second represents the level to which the variance reverts. Todorov (2009) allows for both stochastic volatility and jumps to be reflected in the variance risk premium.
} 
this information is used to construct monthly seasonally adjusted real per capita consumption expenditures on nondurable goods and services. Seasonally adjusted monthly data on the number of employees is obtained from the Bureau of Labor Statistics.

Stock market data is taken from Kenneth French's web page. Monthly data on value-weighted stock market portfolio returns $\left(R_{W}\right)$ and the risk-free rate $\left(R_{f}\right)$ were deflated using the consumption price deflator. We also collect the size and value FamaFrench risk factors $(S M B$ and $H M L)$. Price-dividend ratio in logs $(P D)$ is computed from the original series in Robert Shiller's web page. Additionally, yields for the 10-year Government Bond, the 1-month T-Bill, and the Moody's Baa Corporate Bond have been obtained from the Federal Reserve Statistical Release.

We compute three state variables based on interest rates. $R_{f} S T A T E$ is the riskfree rate after having subtracted its average over the last twelve months as a measure of trend. This de-trended variable can be interpreted as the unexpected shock in the riskfree interest rate. TERM is a term structure slope, computed as the difference between the 10-year Government Bond and 1-month T-Bill yields, and DEFAULT is the difference between Moody's yield on Baa Corporate Bonds and the 10-year Government Bond yield.

Finally, we also use a market-wide illiquidity indicator based on the aggregate illiquidity measure proposed by Amihud (2002), ${ }^{8}$ as the ratio of the absolute daily return over the dollar volume for a given stock, which is closely related to the notion of price

\footnotetext{
${ }^{8}$ The main advantage of Amihud's illiquidity ratio is that it can be easily computed using daily data during long periods of time. Moreover, Hasbrouck (2009) shows that, at least for US data, Amihud's ratio better approximates Kyle's lambda relative to competing measures of illiquidity.
} 
impact, $\operatorname{Illiq}_{i, d}=\frac{\left|R_{i, d}\right|}{D V o l_{i, d}}$, where $\left|R_{i, d}\right|$ is the absolute return and $D V o l_{i, d}$ is the dollar volume of asset $i$ on day $d$, respectively. This measure is averaged monthly and across all $N$ available stocks to obtain the market-wide illiquidity measure for each month $t$,

$$
\operatorname{Illiq}_{m, t}=\frac{1}{N} \sum_{i=1}^{N}\left(\frac{1}{D_{i, t}} \sum_{d=1}^{D_{i, t}} \operatorname{Illiq}_{i, d}\right)
$$

where $D_{i, t}$ is the number of days for which there is data on stock $i$ in month $t{ }^{9}$

We compute monthly series of cumulative returns corresponding to the five maturity intervals of the variance swap for the market return, the three Fama-French factors, and $R_{f} S T A T E$. We also compute monthly series of cumulative growth rates for aggregate non-durable consumption and the number of employees for the five maturity intervals. As in the case of the risk free rate, the relevant information content of TERM, DEFAULT, PD or Illiq $q_{m}$ relies on their unexpected components. Therefore, we compute innovations corresponding to the five maturity intervals as the residual in the regression:

$$
X_{t+\tau}=\alpha_{0}+\alpha_{1} X_{t}+\varepsilon_{t+\tau}^{X^{\tau}}, \quad X=P D, T E R M, D E F A U L T, \text { Illiq }_{m} \text { and } \tau=1,2,3,6,12
$$

With this specification, the idea is to pick up the surprises on these state variables during the life of the swap, from $t$ to $t+\tau .{ }^{10}$

\footnotetext{
${ }^{9}$ We use daily data from CSRP on all individual stocks with at least 15 observations for the ratio within the considered month, except for September 2001, when we just required 12 observations.

${ }^{10}$ To have numerical values closely resembling rate of return units, the residuals of the illiquidity measure are standardized by dividing by ten times their sample standard deviation and adding one. See Márquez et al. (2013) for further details.
} 


\section{Hedging Performance of the Variance Risk Premium against Economic Risks}

The variance swaps offer hedging against the negative equity returns occurred during recession periods because these bust times are characterized by high volatility. Therefore, variance swap rates contain risk neutral expectations about future market conditions. Several papers link the variance risk premium to future stock market behavior. Bollerslev et al. (2010) show that the variance risk premium is a strong predictor of stock market returns at short horizons. Nieto and Rubio (2011) also show the predicting ability of the variance risk premium at the shortest horizon analyzed in their paper, although this forecasting capacity disappears at long horizons. Finally, Drechsler and Yaron (2011), and Zhou (2009) rationalize the statistical predictive power of the variance risk premium within the long-run risk model of Bansal and Yaron (2004) and show theoretically that the variance risk premium is linked to uncertainty about economic fundamentals, deriving the conditions under which the premium predicts future market returns. ${ }^{11}$

Our approach is different. To the best of our knowledge, there are not papers showing directly the hedging capacity of the variance risk premium regarding future financial and macroeconomic risks. Moreover, we analyze how this hedging ability changes for different investment horizons (variance swap maturities).

To analyze the ability of the variance swap contract to hedge the various types of aggregate risk, we estimate linear regressions,

$$
V R P_{t, t+\tau}=\alpha+\beta^{\prime} X_{t, t+\tau}+\varepsilon_{t, t+\tau} \quad(\tau=1,2,3,6 \text {, and 12), }
$$

\footnotetext{
${ }^{11}$ In particular, Zhou (2009), explicitly avoids the long-run component in consumption growth, and attributes the higher order time-variation in risk premia to the stochastic volatility-of-volatility in consumption growth. His theoretical approach is capable of reproducing the variance risk premium skewness and kurtsosis without introducing jumps.
} 
where $X$ is a vector of variables representing a specific type of economic or financial risk. The time indexes in (8) reflect the fact that we are looking for the possibility that the variance swap offers advanced coverage for risk that may materialize over the maturity life of the swap contract.

We consider different state variables grouped into three kinds of risk: equity market risk, interest rate risk, and business cycle risk. The first group of variables contains the three Fama-French (1993) factors $\left(R_{W}-R_{f}, S M B, H M L\right)$ and the innovations in the price-dividend ratio $(P D)$. In the second group we consider three variables related to the interest rate risk: the fluctuations in the detrended level of the risk-free real interest rate ( $\left.R_{f} S T A T E\right)$, the surprises in the slope of the yield curve (TERM), and the innovations in the default premium $(D E F A U L T)$. Finally, we use the growth rate of per capita real aggregate non-durable consumption, the total employment growth rate, and the innovations in the market-wide illiquidity measure as business cycle indicators.

The hedging ability of the variance swap against equity market risk comes from the definition of the contract. The basic intuition behind the variance swap is that investing in volatility appears attractive because volatility shocks are known to be negatively correlated with stock index returns. Thus, adding volatility exposure to an equity portfolio should improve risk diversification. In that sense, we would expect a negative relationship between the variance risk premium and any indicator of stock market risk. Moreover, the volatility of a stock market index increases during recessions, so that a variance swap contract will provide the desired protection if the variance risk premium is higher in anticipation of these stressed periods. For that reason we also analyze the relationship between the variance risk premium and variables representing other types of risk as proxied by interest rates or business cycle indicators. 
It should be noted that if the variance swap fulfills its role as a hedge against volatility, it will bear a negative relationship with any variable indicating "good news", and a positive relationship with any indicator of "bad news".

The results regarding the first group of variables, namely equity risks, are reported in Panel A of Table 2. Despite the construction of the $S M B$ and $H M L$ factors followed by Fama and French (1993), we correct for the possibility that the four variables employed in this group may share common information. Given the assumption that the main source of risk comes from market return variability, we work with the components of $S M B, H M L$ and $P D$ orthogonal to $\left(R_{W}-R_{f}\right)$. These orthogonal factors are obtained as the residuals of the regression of each factor on the market factor:

$$
X_{t}^{+}=X_{t}-\hat{\beta}_{0}-\hat{\beta}_{1}\left(R_{W t}-R_{f t}\right), X=S M B, H M L, P D,
$$

and we denote them with + sign in Table 2 . We expect a negative relationship between the variance risk premium and all the components in this group.

The second group of variables considers three potential sources of risk based on interest rates: $X=\left[R_{f} S T A T E, T E R M, D E F A U L T\right]$. The detrended real interest rate acts as a proxy for an interest rate surprise, and then we expect a positive relationship with the variance risk premium. A flattening of the term structure is known to anticipate a recession, so a potentially negative relation between the variance risk premium and the innovation in the TERM is expected. Finally, we also expect a positive relationship between the variance risk premium and surprises in the DEFAULT factor. The estimation results are presented in Panel B of Table 2. We use the components of TERM and DEFAULT that are orthogonal to $R_{f} S T A T E$, considered the main source of risk in this group. Such components are estimated as in equation (9). 
Thirdly, we consider the possibility that variance swaps might provide a hedge against negative developments in the business cycle. We use the growth rate of per capita real aggregate non-durable consumption, total employment growth rate, and the market-wide illiquidity surprises as business cycle indicators. In this case, we analyze the relationship between the variance risk premium and each one of these three variables individually with the estimation results reported in the three sections of Panel C of Table 2. We expect a negative relationship between the variance swap premium and the future growth rates of the two macroeconomic indicators, as well as a positive relation with our measure of aggregate illiquidity shocks.

All panels in Table 2 report slope estimates, autocorrelation robust standard errors in parenthesis, and the adjusted $R^{2}$ of the regressions. For comparison, the last row of panels $\mathrm{A}$ and $\mathrm{B}$ also provides the $R^{2}$ of a regression that only considers the main source of risk, namely the excess market return and the detrended risk free rate, respectively.

Generally speaking, our results show widespread evidence in favor of variance swaps playing a significant role as a hedge against a variety of risks. Panel A of Table 2 shows the variance risk premium to be strongly and negatively related to market returns at all maturities. It also shows a negative relationship with $P D$ that is generally significant for the different horizons, but especially relevant for the longer maturities. The negative estimated coefficients suggest that the variance swap may provide a significant hedge against market risk and also against the shocks to the dividend-price ratio which are not correlated with the market index. Regarding the Fama-Frech factors, we find that the $V R P$ is negatively correlated with $S M B$ but only for the longest horizon. Finally, the relation between $V R P$ and the component of $H M L$ that is orthogonal to the 
market return is positive but not statistically significant. Comparing the last two rows of Panel A, we see that variance swaps seem to offer hedging possibilities against risks other than changes in the index return for longer horizons. The most remarkable case is the 12- month horizon, where the addition of $S M B$ and $P D$ (and $H M L$ ) to the market return increases the adjusted $R^{2}$ by $26 \%$.

Panel B of Table 2 shows that coefficients regarding factors related to interest rate risk are generally estimated with low precision. Over the whole spectrum of maturities considered by the analysis, the variance risk premium seems to anticipate significantly the one-month future fluctuation in $R_{f} S T A T E$ and the 6-months unexpected change in DEFAULT. The sign of the hedging relations are as expected. The comparison of adjusted $R^{2}$ values at the bottom of Panel B of Table 2 shows that the correlation of the variance risk premium with the specific risk component in DEFAULT seems to be important, especially for the 6-months horizon.

Panel C of Table 2 contains the evidence on business cycle risks. It is interesting to see that the variance risk premium displays a significant negative relationship with the consumption growth rate at all maturities except the shortest one. Hence, long positions on the variance swap contract seem to provide insurance not only with respect to market equity risk, but also to real macroeconomic risks. ${ }^{12}$ In fact, the adjusted $R^{2}$ with consumption growth at the 12-month horizon is substantially higher than most of the reported $R^{2}$ based on any other single indicator. It might be thought that the correlation we present is spurious, consumption growth being a proxy for the stock market or interest rates. However, an additional analysis with multiple regressions indicates that this is not the case. Panel $\mathrm{C}$ also shows that the relation between $V R P$ and

\footnotetext{
${ }^{12}$ This finding is potentially interesting from the asset pricing point of view, since any equilibrium model would imply a correlation between the excess return on the swap, captured here by the variance risk premium, and consumption growth.
} 
employment growth is negative but it is much weaker than the relationship with consumption growth. For intermediate horizons, VRP is positively related to aggregate illiquidity shocks, indicating that the variance swap provides hedge against aggregate illiquidity risk. Interestingly, a multiple regression analysis (not shown in the paper) reveals that this positive relationship is maintained if we add the market return, so that market-wide illiquidity seems to be an additional risk factor over and above market risk.

By and large, the evidence in this section indicates that the variance risk premium is able to anticipate different kinds of risk embedded in traditional state variables. Such risks go beyond the type of risk in stock market returns or in the level of interest rates. There is also a significant relation between $V R P$ and macroeconomic risk measures; the case of consumption growth is especially relevant.

\section{Hedging and Non-Normality}

Recent empirical work has consistently shown that risk neutral volatility is higher, on average, than physical return volatility. ${ }^{13}$ Little work has been done on theoretically characterizing the distance between both types of volatility, with Bakshi and Madan (2006) and Chabi-Yo (2012) being two examples. In both cases, the $V R P$ is derived as a function of standard deviation, skewness and kurtosis of equity returns. Therefore, the magnitude and behaviour over time of the $V R P$ may also be empirically related to higher order moments of the equity return distribution. The issue we want to investigate next is whether or not the hedging ability of variance swaps is related to these higher order moments. To answer this question, we rely on the Chabi-Yo (2012) model of the $V R P$. We analyse the extent to which higher order moments of the distribution of equity returns determine the $V R P$ for the different swap maturities, and whether these moments

\footnotetext{
${ }^{13}$ See Bakshi and Kapadia (2003), Jiang and Tian (2005), Carr and Wu (2009) and Bollerslev et al. (2011) among others.
} 
are behind the behaviour over time of the different state variables that the swap is able to hedge.

Chabi-Yo (2012) obtains a stochastic discount factor in which coskewness and the market volatility risk factors are endogenously determined. His model is an extension of the coskewness models of Rubinstein (1973), Kraus and Litzenberger (1976), and Harvey and Siddique (2000) in which the expected risk premium for any stock is determined not only by coskewness but also by the co-movement between the market volatility and the return on the stock. In addition, this pricing expression explicitly depends on the cross-sectional average of investors risk tolerance and on the weighted average of their preferences for skewness.

An implication of the Chabi-Yo's asset pricing model, especially relevant for our purposes, is that negative skewness and high excess kurtosis, together with a high level of preference for skewness are the two main sources of negative variance risk premium. Moreover, as long as the skewness preference parameter is higher than one, a high correlation of the market variance with the squared market return generates an even more negative variance risk premium. Under this model, the variance risk premium is given by

$$
V R P_{t, t+\tau}=\lambda_{0}+\lambda_{W}\left(\sigma_{W t, t+\tau} S_{W t, t+\tau}\right)+\lambda_{S K D}\left(\sigma_{W t, t+\tau}\left(K_{W t, t+\tau}-1\right)\right)+\lambda_{V O L} v_{W t, t+\tau}
$$


where $\sigma_{W}, S_{W}, K_{W}$ represent the standard deviation, skewness, and kurtosis of the market return respectively, $v_{W t, t+\tau}=\operatorname{Cov}_{t}\left(\sigma_{W t, t+\tau}^{2}, R_{W t, t+\tau}^{2}\right) / \operatorname{Var}_{t}\left(\sigma_{W t, t+\tau}^{2}\right)$ and $\lambda_{W}>0$, $\lambda_{S K D}<0$ and $\lambda_{V O L}<0 .{ }^{14}$

We estimate equation (10) for each swap maturity using as proxies for conditional standard deviation, skewness and kurtosis the corresponding sample moments computed from 30-minute intra-daily data between 9 a.m. to 3 p.m. on S\&P 500 index returns for the time interval defined by each swap maturity. ${ }^{15}$ Results are reported in Panel A of Table 3. The table displays coefficient estimates, autocorrelationrobust standard errors in parenthesis, and the $R^{2}$ for three different maturities of the variance swaps: 1 month, 6 months and 12 months. ${ }^{16}$ The overall fit of the model improves with the maturity, as indicated by the $R^{2}$ statistics. Regarding the estimates of individual coefficients, the cross product of standard deviation and kurtosis is the only variable with a statistically significant coefficient and the negative expected sign at the 1- and 6-month horizons. Other things equal, as more volatility uncertainty is expected in the form of higher kurtosis, the variance swap rate becomes higher and the variance risk premium more negative. At the shortest horizon, the coefficient associated with the cross product of standard deviation and skewness is estimated with very little precision. As the time horizon increases, the estimated coefficient of this cross product increases drastically although it is only significant for the longest maturity. On the other hand, the estimated effect of the cross product of standard deviation and kurtosis is quite stable

\footnotetext{
${ }^{14}$ A previous version of the Chabi-Yo's (2012) work is the Chabi-Yo's (2009) SSRN working paper. This working paper includes in the main text, not only the equation for pricing returns but also the equation for pricing variance risk (equation 19). Details regarding the derivation can be found in the Appendix of Chabi-Yo (2009).

${ }^{15}$ Alternatively, we also followed the approach in León et al. (2005) for estimating conditional variance, skewness, and kurtosis. Results confirm the evidence presented in Tables 3 and 4 and are not provided for space reasons. Details about the estimation procedure and/or the results are available upon request.

${ }^{16}$ In order to save space, and for all tests of this section (Tables 3 and 4), we only provide results regarding three swap maturities, 1, 6 and 12 months. The results related to the other two horizons are available upon request.
} 
but a loss of precision weakens its statistical significance at the longest horizon. It must be noted that the skewness takes a very low value during our sample period, with average values for one-, 6- and 12-months horizons of $0.066,-0.150$, and -0.117 , respectively.

Our results are consistent with the evidence provided in Bakshi and Madan (2006). The authors propose a model for volatility spreads by simply allowing a Taylor expansion of order 3 for the pricing kernel. Under this assumption, the $V R P$ is fully specified with relative risk aversion, variance, skewness and kurtosis of returns. ${ }^{17}$ Using data with one-month maturity, they estimate the model (relative risk aversion is the single parameter) and test the over-identifying restrictions in three cases: the unrestricted model, assuming that excess kurtosis is zero, and assuming that there is no skewness in equity returns. They find that while the elimination of the skweness has very little effects on the value and precision of the estimate of the risk aversion coefficient, when zero excess kurtosis is imposed, very large (arguably implausible) values of relative risk aversion are needed to reconcile the variance risk premium with the relation between the physical and the risk-neutral densities.

Panels B, C and D of Table 3 contain the results from equation (10) when replacing the $V R P$ by different state variables. The idea is to analyze whether the fears to deviations from Normality are also related to standard measures of financial and macroeconomic risks. Specifically, we now estimate the regression:

$$
Y_{t, t+\tau}=\lambda_{0}+\lambda_{W}\left(\sigma_{W t, t+\tau} S_{W t, t+\tau}\right)+\lambda_{S K D}\left(\sigma_{W t, t+\tau}\left(K_{W t, t+\tau}-1\right)\right)+\lambda_{V O L} v_{W t, t+\tau}+\mu_{t, t+\tau}
$$

\footnotetext{
${ }^{17}$ In fact, the specific model that they derive under power utility has very similar implications to the Chabi-Yo’s pricing equation.
} 
where the dependent variable $(Y)$ represents a specific type of economic or financial risk. Consistently with Section 4, Panel B reports results for variables related to equity risks, $\left(R_{W}-R_{f}\right), S M B, H M L$ or $P D$; in Panel C the dependent variable is $R_{f} S T A T E$, TERM or DEFAULT, and Panel D refers to the business cycle indicators: consumption growth, employment growth and the aggregate illiquidity measure.

A general result in all panels from B to D of Table 3, which is also consistent with the findings of Panel A, is that the relation between these risk factors and the moments of the distribution of market returns becomes stronger for longer horizons, as shown by the $R^{2}$ statistic. The high values of the $R^{2}$ statistic of $39 \%$ for $R_{f} S T A T E, 58 \%$ for $D E F A U L T$ or $35 \%$ for illiquidity risk at the 12 -month horizon are remarkable. To further illustrate this point, Figure 2 displays the actual values of illiquidity and default risks at the 12-month horizon together with their fitted values from regression (11).

The statistical significance of the individual coefficients associated with skewness and/or kurtosis depends upon the indicator being explained and the horizon but, as in the case of the $V R P$ in Panel A, the third explanatory variable in equation (11) is not relevant. For 1- and 6-month horizons, the dominant variable is the product of standard deviation and kurtosis. It significantly explains the value factor $(H M L)$ at the shortest maturity, the market return, the risk free rate and the TERM spread at the 6month maturity, and DP, DEFAULT, and the three business cycle indicators at both one- and 6-month horizons. On the other hand, the variable associated with the skewness is also relevant for explaining the market return and the default premium for all horizons.

In order to analyse which of the two cross products (either skewness or kurtosis) is the explanatory variable with more information content, we estimate again equations 
(10) and (11) without either one of the three explanatory variables, to analyse the decrease in the $R^{2}$ relative to the unrestricted regression. The results are contained in Table 4 where the first block provides the results for $V R P$, and the following four blocks display the results regarding the four risk factors for which the $V R P$ presents the highest hedging ability. For comparability, the first row in each block provides again the $R^{2}$ from the estimation of the unrestricted regression.

With respect to $V R P$, the kurtosis variable is relevant for the three maturities, but its overall explanatory power is especially relevant at the one-month horizon. Once again, this finding is consistent with the results in Bakshi and Madan (2006). The variable based on skewness turns out to be the most important one for the 12-month maturity. Regarding the rest of dependent variables, the $R^{2}$ statistic drops substantially when we take the product of standard deviation and kurtosis out of the regression for all horizons, with the exception of the market return and the one-month maturity. In the case of consumption growth, the decrease in $R^{2}$ is more pronounced at the six-month horizon, while the explanatory power of kurtosis seems to be higher at the longest horizon for $P D$. Moreover, the skewness variable is also relevant for explaining $P D$ at all horizons.

Summarizing, our results suggest that the ability of the variance swap to hedge the risk associated to the market return, the dividend-price ratio, the aggregate consumption growth, the aggregate illiquidity risk, and even default risk, might come from the relationship of these financial and macroeconomic risk factors to the kurtosis of equity returns. Additionally, the power of variance swaps to hedge against market risk at the one-month horizon and against the price-dividend risk at all horizons may 
also be associated with the relation between these variables and the skewness of the returns.

\section{Robustness Tests}

Next, we repeat the estimations in Sections 4 and 5 introducing two variants. First, we change the estimation of the realized variance using daily returns instead of intra-daily returns. Second, for the one-month maturity, we extend the sample period as much as possible such that it includes the recent financial crisis.

\subsection{Estimating Realized Variance with Daily Returns}

Despite the fact that the academic literature tends to apply high-frequency data when estimating variance risk premia, the real payoffs of these contracts are based on realized variance estimated with daily log-returns. It is therefore necessary to check the robustness of our previous results when daily data rather than intra-daily data are used in the estimation of realized variances.

Figure 3 shows that the variance risk premia for 1-, 6- and 12-month maturities estimated under both procedures are very close to each other. If anything, and particularly for the longest horizons, the variance risk premium is even higher when realized variances are estimated with daily log-returns.

To be more precise, we repeat all our estimations using daily data to estimate realized variance and the higher moments of returns. We achieve the same qualitative and economic implications. To illustrate this, Table 5 reports the estimation results from the Chabi-Yo equation (10). Once again, at the three horizons, the cross product of standard deviation and kurtosis is the only variable with a statistically significant coefficient and the negative expected sign. Indeed, the coefficients are estimated with 
more precision and $R^{2}$ are a slightly higher than in Panel A of Table 3. On the other hand, the coefficient associated with the cross product of standard deviation and skewness is estimated with very little precision for all horizons in this case. Therefore, it is confirmed that the variance risk premium may be generated by the desire of investors to hedge against leptokurtic return distributions. The rest of the empirical results maintain the conclusions reported in the previous sections. ${ }^{18}$

\subsection{Including the Recent Global Financial Crisis Period}

A natural criticism to our work might be that the selected sample period, from January 1996 to January 2007, excludes the last financial crisis, with volatility having a large spike during the fall of 2008. Therefore, we might miss the opportunity to investigate the hedging performance of variance swaps during a period characterized by the circumstances for which these assets are intended. However, data on variance swap rates were obtained from the Bank of America and an updated data sample is unavailable.

To include the economic crisis in our analysis, at least for the one month maturity, we resort to the data kindly provided by Hao Zhou in his personal webpage. ${ }^{19}$ For the period between 1990 and 2012, the author provides end-of-month VIX-squared data as a measure of the risk-neutral expectation of variance and the estimation of the realized variance as the sum of squared 5-minute log returns of the S\&P 500 index over the month. ${ }^{20}$ The strong similarities between VIX and one-month variance swap rates can be observed in Figure 4, which provides histograms and descriptive statistics of

\footnotetext{
${ }^{18}$ The results from all other tables using daily returns in the estimation of realized variances are available upon request.

${ }_{19}^{19}$ www.pbcsf.tsinghua.edu.cn.

20 VIX is a measure of implied volatility in index options that is calculated employing model-free techniques. See CBOE website for details.
} 
both series for our sample period, 1996-2006. Moreover, the linear correlation coefficient between both series is 0.97 , as the top picture in Figure 5 clearly reflects. We use equation (5) to compute the $V R P$ with Zhou's data for the period between January 1990 and November 2012. The bottom picture in Figure 5 displays the obtained $V R P$ together with our shorter series for comparability. As expected, both series are also very similar with a linear correlation coefficient of 0.87 .

Then, we repeat the estimations of Table 2 and Panel A of Table 3 using this updated variable. The new results are reported in Panels A and B of Table 6, respectively. The first block in Panel A refers to equity risks. Again, we find a strong ability in variance swaps to hedge future changes in equity market returns. Indeed, when the crisis period is considered, the $R^{2}$ increases from $15.6 \%$ to $20.3 \%$. As expected, the relation is negative. All other coefficients associated with equity risk variables are also negative, but they are not relevant when we extract the part that is already included in the market return. For the rest of the blocks, the results are consistent with the findings reported in Table 2. For the shortest horizon neither the interest rate variables nor the macroeconomic risks are significantly hedged using variance swaps. Of course, the problem is that we do not have data for longer maturities, which makes it impossible to capture the hedging ability of these variables at longer horizons. However, Figure 5 suggests that the results might be very similar.

Panel B of Table 6 reports estimates of the Chabi-Yo pricing equation for the $V R P$. Once again, the evidence indicates a relevant relation between the $V R P$ and the kurtosis of equity returns. The coefficient is negative, larger in absolute value and it is estimated with more precision than when using the shorter sample. The global fit of the model is also better than in Table 3. The skewness coefficient is again positive and, as it 
was the case for kurtosis, it is now estimated with more precision. Therefore, the results reinforce the conclusion that investors' fears to the high kurtosis of the distribution of equity returns explain the large values of variance swap rates.

\section{Asset Allocation and Volatility Exposure}

In previous sections we have found evidence suggesting a significant hedging ability of variance swaps against a variety of risks, on the one hand, and a significant contribution of the non-normality of the distribution of equity returns to generate the $V R P$. Such results suggest that including volatility exposure in a portfolio can improve the performance in terms of variance, skewness and kurtosis of portfolio returns. We analyse this hypothesis using a performance measure that incorporates simultaneously all these three moments: the modified Value-at-Risk.

Investment in volatility products can be justified by the fear of investors to suffer substantial losses during extreme recession periods. For that reason, we use the Value at Risk $(\operatorname{VaR})$ as a measure of risk that reflects the maximum potential loss that may arise with a given probability. We follow Brière et. al. (2010) who suggest the modified VaR because it considers the possibility that returns are not normally distributed. Specifically, given the probability $\alpha$, the modified $V a R$ is given by

$$
\operatorname{ModVaR}(1-\alpha)=-\left(\mu+\omega_{\alpha} \sigma\right)
$$

where $\mu$ and $\sigma$ are the mean and the standard deviation of returns, and

$$
\omega_{\alpha}=z_{\alpha}+\frac{1}{6}\left(z_{\alpha}^{2}-1\right) S+\frac{1}{24}\left(z_{\alpha}^{3}-3 z_{\alpha}\right)(K-3)-\frac{1}{36}\left(2 z_{\alpha}^{3}-5 z_{\alpha}\right) S^{2}
$$


where $z_{\alpha}$ is the $\alpha$-quantile of the standard normal distribution, $S$ is the skewness and $K$ is the kurtosis. The modified $V a R$ will be higher if the portfolio returns distribution is negatively skewed and/or is leptokurtic.

Our portfolio analysis consists of comparing two portfolios: a 100\% position on the equity market portfolio and an alternative portfolio that combines the equity market and the variance swap. The concluding comparison will be done in terms of modified $V a R$. We have already pointed out that the average $V R P$ is negative implying a negative mean returns from a long position in variance swaps. For that reason, our goal now is to explain why it makes sense to include variance swaps in a portfolio even if that should be expected to decrease its mean return. We compute the out-of-sample modified VaR of the two portfolios, using a rolling window on past data to calibrate the process for swap returns and to estimate the optimal portfolio weights. ${ }^{21}$ Next, we describe this procedure with some more detail.

Let $T$ be the total size of our sample data. For each month $t$, for $t=61, \ldots, T-1$, we proceed as follows:

1) Using data on $V R P$ and $R_{W}$ for the period $[t-60, t]$, we calibrate the leverage $\left(L_{t}\right)$ of the variance swap by setting the modified $V a R$ of the $V R P$ to the modified $V a R$ of the equity portfolio. Then, we use this leverage coefficient to transform the $V R P$ payoff into $V R P$ returns:

$$
R_{V R P j}=R_{f j}+L_{t} * V R P_{j}, \quad \text { for } j=t-60, \ldots, t+1 .
$$

2) Using data on $R_{W}$ and $R_{V R P}$ for the period [ $t-60, t$ ], we solve for the optimal weights that minimize the modified $V a R$ of the resulting portfolio. We denote by

\footnotetext{
${ }^{21}$ Along this Section, the word "optimal" refers to the solution to the problem of minimizing the portfolio modified $\mathrm{VaR}$.
} 
$X_{W t}$ and $\left(1-X_{W t}\right)$ the weights assigned to the equity market portfolio and the $V R P$ respectively.

3) Using the weights estimated in step 2, we compute the optimal portfolio return for the following month as

$$
R_{P t+1}=X_{W t} R_{W t+1}+\left(1-X_{W t}\right) R_{V R P t+1} .
$$

Finally, we have a time series of optimal portfolio returns, $R_{P}$, for the period [ $t+$ $1, T]$ that it is compared to the return of the equity market portfolio for the same out-ofsample period. This is repeated for three alternative maturities: 1, 6 and 12 months and also for the extended sample period (1990-2012) by using Zhou's data. The results are contained in Table 7.

The results for the shorter sample period (1996-2006) show that the portfolio that includes the $V R P$ has negative mean returns but a lower standard deviation than the $100 \%$ investment in the equity market portfolio. The range of dispersion between the minimum and maximum returns is also narrower for the enlarged portfolio and, with the exception of the one-month maturity, the maximum loss (minimum return) is smaller. The percent reduction in standard deviation and the tightening of the range of values increases with maturity, suggesting that the hedging ability of variance swaps is higher for longer maturities. The portfolio that includes variance swaps also shows higher negative skewness and higher excess kurtosis than the competing equity portfolio. The combination of all of these moments produces a relatively lower modified $\mathrm{VaR}$ for the enlarged portfolio in the 6- and 12- month maturities. The analysis of the extended period (1990-2012) shows even better results in terms of the reduction in the standard deviation and in the range between the maximum and minimum returns when including the variance swap. The main difference when using Zhou's data is the larger excess 
kurtosis of the enlarged portfolio. The overall final result is a decrease in the modified $\operatorname{VaR} .^{22}$

For a more detailed comparison between the modified $\mathrm{VaR}$ of the two portfolios, we estimate the distribution properties of their difference using a bootstrapping procedure. We start by computing the sample mean, standard deviation, skweness, and kurtosis of the observed data for $R_{W}$ and $V R P$ over the whole period. Then, we generate 1000 random samples for each $R_{W}$ and $V R P$ from the distribution in the Pearson system that matches their respective sample moments. ${ }^{23}$ Using the calibrated values for $L$ in step 1 above, the generated samples of $V R P$ are transformed into returns with equation (14), and using the estimated weights in step 2 above we obtain the return on the combined portfolio as in equation (15). The modified $V a R$ is then calculated for each of the 1000 samples for $R_{W}$ and for each of the 1000 samples for the portfolio that combines $R_{W}$ and $R_{V R P}$. Last row in Table 7 provides the median, the $95 \%$ confidence interval, and the probability of negative values for the difference between the two modified VaRs (Mod. $V a R_{R w}-M o d$. $\left.V a R_{R w+V R P}\right)$. In terms of their median values, the $V a R$ is always reduced when the portfolio contains the $V R P$. The confidence intervals indicate that the density of the difference concentrates around positive values, suggesting a lower modified $V a R$ for the enlarged portfolio in probabilistic terms. Indeed, the percentage of realizations for which the opposite happens decreases with the maturity of the swap, being close to zero for the period that includes the recent crisis. Therefore, we can conclude that the aim of reducing the modified $V a R$ is achieved by including the variance swap in the investment portfolio.

\footnotetext{
${ }^{22}$ The differences between our results and Brière et. al. (2010) findings can be explained by two reasons. On the one hand, instead of conducting a rolling estimation procedure, they divide the sample into two static sub-periods for the estimation of in-sample and out-of-sample performance. Our iterative results indicate that both optimal weights and sample moments display large variations for different sample subperiods. On the other hand, these authors define a strategy based on a short variance swap position and, consequently, the mean and Sharpe ratio are positive for their definition of variance swap returns.

${ }^{23}$ See Elderton and Johnson (1969).
} 
It is interesting to further explore the case of the longer 1990-2012 sample period because it includes the recent and extreme financial crisis of 2008. The lofty jump in both the equity volatility and $V R P$ during September 2008, displayed in Figure 5, generates a large kurtosis in swap returns and an excess kurtosis of 6 in the optimal portfolio that includes the variance swap. However, the reduction in the standard deviation of the portfolio compensates the large kurtosis, and the modified $V a R$ turns out to be lower when investing in the variance swap. In fact, at the time of the jump, the optimal portfolio consists of going short on the equity market portfolio and investing more than $100 \%$ in the swap. Figure 6 displays the optimal weight on equity as estimated each month with the updated data window. The optimal weight is around $40 \%$ in equity (60\% in the swap) until the peak of the crisis. At that point, the equity weight drops to negative values and stays close to zero for the rest of the sample period. Hence, our results suggest that, in times of financial distress, the optimal investment in terms of modified $V a R$ is to go long on the variance swap and slightly short on the market portfolio. Once again, this clearly shows the hedging ability of this financial asset. ${ }^{24}$

\section{Conclusions}

We have analysed the hedging ability of variance swap contracts against a variety of factors representing both financial and macroeconomic risks. We have found that these derivative contracts are particularly useful for hedging the variability in stock returns and the price-dividend ratio at short investment horizons, the risk associated to the size factor at 12-months maturity, the default risk at 6-month horizon, and the

\footnotetext{
${ }^{24}$ Hafner and Wallmeier (2008) conduct a portfolio analysis for a set of assets made up by the stock index, the variance swap and the risk free rate, where the objective function in the optimization problem also depends on higher order moments. Using data for German DAX variance swaps for the period between 1995 and 2004, they show that the objectives of minimizing kurtosis or maximizing skewness are achieved for positive weights on the variance swap.
} 
macroeconomic risk contained in the changes of consumption growth beyond 3-month horizons, and the illiquidity risk for investment horizons between 2 and 6 months.

We have also shown that the variance risk premium at different horizons responds to investors' fears to time-varying deviations from Normality in returns, especially concerning the kurtosis of the return distribution. Furthermore, we have provided evidence showing that these higher return moments also explain the time variation of the mentioned financial and macroeconomic variables that the swap is able to hedge.

In consistency with the fact that variance swaps hedge against risks associated to moments over and above the mean and the standard deviation of returns, an asset allocation exercise shows that including variance swaps in an equity portfolio reduces the out-of-sample modified Value-at-Risk of the portfolio. 


\section{References}

Amengual, D. (2009), The Term Structure of Variance Risk Premia, Working Paper, Department of Economics, Princeton University.

Amihud, Y. (2002), Illiquidity and Stock Returns: Cross-Section and Time-Series Effects, Journal of Financial Markets 5, 31-56.

Bakshi, G. and N. Kapadia (2003), Delta hedged gains and the negative market volatility risk premium, Review of Financial Studies 16, 527-566.

Bakshi, G. and D. Madan (2006), A Theory of Volatility Spreads, Management Science 52, $1945-1956$.

Bansal, R., and A. Yaron (2004), Risks for the Long-Run: A Potential Resolution of Asset-Pricing Puzzles, Journal of Finance 59, 1481-1509.

Bollerslev, T., G. Tauchen and H. Zhou (2010), Expected stock returns and variance risk premia, Review of Financial Studies 22, 4463-4492.

Bollerslev, T., M. Gibson and H. Zhou (2011), Dynamic Estimation of Volatility Risk Premia and Investor Risk Aversion from Option-Implied and Realized Volatilities, Journal of Econometrics 160, 102-118.

Brière, M., A. Burgues and O. Signori (2010), Volatility Exposure for Strategic Asset Allocation, Journal of Portfolio Management 36, 105-116.

Carr, P. and L. Wu (2009), Variance Risk Premia, Review of Financial Studies 22, 1311-1341.

Chabi-Yo, F. (2009), Pricing Kernels with Coskewness and Volatility Risk, SSRN Working Paper, http://papers.ssrn.com/sol3/papers.cfm?abstract_id=1361926

Chabi-Yo, F. (2012), Pricing Kernels with Stochastic Skewness and Volatility Risk, Management Science 58, 624-640. 
Drechsler, I., and A. Yaron (2011), What's Vol Got to Do with It, Review of Financial Studies 24, 1-45.

Driessen, J., P. Maenhout, and G. Vilkov (2009), The Price of Correlation Risk: Evidence from Equity Options, Journal of Finance 64, 1377-1406.

Egloff, D., M. Leippold, and L. Wu (2010), The Term Structure of Variance Swap Rates and Optimal Variance Swap Investments, Journal of Financial and Quantitative Analysis 45, 1279-1310.

Elderton, W., and N. Johnson (1969), Systems of Frequency Curves, Cambridge University Press.

Fama, E., and K. French (1993), Common Risk Factors in the Returns on Stocks and Bonds, Journal of Financial Economics 33, 3-56.

Hafner, R. and M. Wallmeier (2008), Optimal Investments in Volatility. Financial Markets and Portfolio Management 22, 147-167.

Hasbrouck, J. (2009), Trading Costs and Returns for US Equities: Estimating Effective Costs from Daily Data, Journal of Finance, 64, 3, 1445-1477.

Harvey, C. and A. Siddique (2000), Conditional Skewness in Asset Pricing Tests, Journal of Finance 55, 1263-1295.

Jiang, G. and Y. Tian (2005), The model free implied volatility and its information content, Review of Financial Studies 18, 1305-1342.

Kraus, A., and R. Litzenberger (1976), Skewness Preference and the Valuation of Risky Assets, Journal of Finance 31, 1085-1100.

León, A., G. Rubio, and G. Serna (2005), Autoregressive Conditional Volatility, Skewness and Kurtosis, Quarterly Review of Economics and Finance 42, 599618. 
Márquez, E., B. Nieto, and G. Rubio (2013), Consumption, Liquidity, and the CrossSectional Variation of Expected Returns, forthcoming in the International Review of Economics and Finance.

Nieto, B., and G. Rubio (2011), The Volatility of Consumption-Based Stochastic Discount Factors and Economic Cycles, Journal of Banking and Finance 35, 2197-2216.

Rubinstein, M. (1973), The Fundamental Theorem of Parameter-Preference Security Valuation, Journal of Financial and Quantitative Analysis 8, 61-69.

Todorov, V. (2009), Variance Risk Premia Dynamics: The Role of Jumps, Review of Financial Studies, 23, 1, 345-383.

Vilkov, G. (2008), Variance Risk Premium Demystified, Working Paper, INSEAD.

Zhou, H. (2009), Variance Risk Premia, Asset Predictability Puzzles, and Macroeconomic Uncertainty, SSRN Working Paper, http://papers.ssrn.com/sol3/papers.cfm?abstract_id=1400049 
Table 1

Variance Risk Premia: Descriptive Statistics, January 1996-January 2007

\begin{tabular}{|c|c|c|c|c|c|}
\hline \multicolumn{6}{|c|}{ Panel A: Descriptive Statistics } \\
\hline$V R P_{t, t+\tau}$ & $\tau=1$ month & $\tau=2$ months & $\tau=3$ months & $\tau=6$ months & $\tau=12$ months \\
\hline Mean & -0.159 & -0.168 & -0.179 & -0.199 & -0.225 \\
\hline Median & -0.152 & -0.141 & -0.146 & -0.144 & -0.175 \\
\hline Maximun & 0.700 & 0.525 & 0.453 & 0.372 & 0.184 \\
\hline Minimum & -0.810 & -0.837 & -0.955 & -1.106 & -1.091 \\
\hline \multicolumn{6}{|c|}{ Panel B: Linear Correlations } \\
\hline & $\tau=1$ month & $\tau=2$ months & $\tau=3$ months & $\tau=6$ months & $\tau=12$ months \\
\hline$\tau=1$ month & 1 & 0.830 & 0.725 & 0.569 & 0.450 \\
\hline$\tau=2$ months & & 1 & 0.951 & 0.828 & 0.714 \\
\hline$\tau=3$ months & & & 1 & 0.913 & 0.790 \\
\hline$\tau=6$ months & & & & 1 & 0.912 \\
\hline$\tau=12$ months & & & & & 1 \\
\hline
\end{tabular}

$V R P$ is the variance risk premium associated with the alternative horizons of the variance swap contract going from 1 to 12 months. It is computed as the difference between the ex-post realized variance at the end of the swap contract and the currently observed variance swap rate. The numbers in Panel A represent these differences, as a percentage and on a monthly basis. 
Table 2

The Hedging Ability of the Variance Swap Contract

\begin{tabular}{|c|c|c|c|c|c|}
\hline \multicolumn{6}{|c|}{ Panel A: Equity Risks } \\
\hline & $\tau=1$ month & $\tau=2$ months & $\tau=3$ months & $\tau=6$ months & $\tau=12$ months \\
\hline$R_{W}-R_{f}$ & $\begin{array}{c}-1.494 * * * \\
(0.332)\end{array}$ & $\begin{array}{c}-3.191 * * * \\
(0.722)\end{array}$ & $\begin{array}{c}-4.608 * * * \\
(1.051)\end{array}$ & $\begin{array}{c}-6.322 * * * \\
(1.559)\end{array}$ & $\begin{array}{c}-4.138 * * \\
(1.905)\end{array}$ \\
\hline$S M B^{+}$ & $\begin{array}{l}-0.348 \\
(0.421)\end{array}$ & $\begin{array}{c}0.014 \\
(0.732)\end{array}$ & $\begin{array}{c}0.491 \\
(0.884)\end{array}$ & $\begin{array}{l}-2.024 \\
(1.479)\end{array}$ & $\begin{array}{c}-7.693^{* * *} \\
(1.641)\end{array}$ \\
\hline$H M L^{+}$ & $\begin{array}{l}-0.177 \\
(0.603)\end{array}$ & $\begin{array}{c}0.607 \\
(0.779)\end{array}$ & $\begin{array}{c}1.233 \\
(0.965)\end{array}$ & $\begin{array}{c}2.545 \\
(1.595)\end{array}$ & $\begin{array}{c}2.853 \\
(2.584)\end{array}$ \\
\hline$P D^{+}$ & $\begin{array}{l}-1.018^{*} \\
(0.593)\end{array}$ & $\begin{array}{l}-0.944 * \\
(0.586)\end{array}$ & $\begin{array}{c}-1.222^{* * *} \\
(0.442)\end{array}$ & $\begin{array}{c}-1.448^{* * *} \\
(0.422)\end{array}$ & $\begin{array}{c}-1.020 * * * \\
(0.366)\end{array}$ \\
\hline Adj. $R^{2}$ & 0.180 & 0.303 & 0.391 & 0.402 & 0.328 \\
\hline $\operatorname{Adj} . R^{2}\left(R_{W}\right)$ & 0.156 & 0.290 & 0.350 & 0.262 & 0.067 \\
\hline \multicolumn{6}{|c|}{ Panel B: Interest Rate Risks } \\
\hline & $\tau=1$ month & $\tau=2$ months & $\tau=3$ months & $\tau=6$ months & $\tau=12$ months \\
\hline RfState & $\begin{array}{c}11.488^{* * *} \\
(5.775)\end{array}$ & $\begin{array}{l}\text { 18.696* } \\
(11.438)\end{array}$ & $\begin{array}{c}20.083 \\
(17.253)\end{array}$ & $\begin{array}{c}36.137 \\
(31.710)\end{array}$ & $\begin{array}{c}15.392 \\
(52.852)\end{array}$ \\
\hline$T E R M^{+}$ & $\begin{array}{l}-20.889 \\
(29.272)\end{array}$ & $\begin{array}{l}-54.925 \\
(52.716)\end{array}$ & $\begin{array}{l}-43.555 \\
(36.877)\end{array}$ & $\begin{array}{c}29.656 \\
(31.687)\end{array}$ & $\begin{array}{c}39.932 \\
(43.916)\end{array}$ \\
\hline$D E F A U L T^{+}$ & $\begin{array}{l}381.713^{*} \\
(213.775)\end{array}$ & $\begin{array}{c}163.001 \\
(227.526)\end{array}$ & $\begin{array}{c}238.512 \\
(158.453)\end{array}$ & $\begin{array}{c}326.576 * * * \\
(124.965)\end{array}$ & $\begin{array}{c}111.358 \\
(103.321)\end{array}$ \\
\hline $\operatorname{Adj} . R^{2}$ & 0.059 & 0.050 & 0.079 & 0.148 & 0.010 \\
\hline $\operatorname{Adj} . R^{2}\left(R_{f}\right)$ & 0.008 & 0.010 & 0.000 & 0.005 & -0.007 \\
\hline \multicolumn{6}{|c|}{ Panel C: Business Cycle Risks } \\
\hline & $\tau=1$ month & $\tau=2$ months & $\tau=3$ months & $\tau=6$ months & $\tau=12$ months \\
\hline Consumption & -3.156 & $-24.182 * * *$ & $-58.021 * * *$ & $-133.361^{* * *}$ & $-170.968 * * *$ \\
\hline Growth & $(4.990)$ & (9.418) & (19.642) & (34.654) & $(47.427)$ \\
\hline Adj. $R 2$ & -0.005 & 0.031 & 0.106 & 0.256 & 0.302 \\
\hline Employment & 3.475 & -6.121 & -18.830 & -32.446 & -40.748 \\
\hline Growth & $(15.431)$ & (20.171) & $(24.437)$ & (29.385) & $(30.740)$ \\
\hline Adj. $R^{2}$ & -0.007 & -0.006 & 0.004 & 0.020 & 0.038 \\
\hline Agg. Illiq. & 0.198 & $0.256 * *$ & $0.292 * * *$ & $0.249 * *$ & 0.013 \\
\hline Shocks & $(0.133)$ & $(0.117)$ & $(0.117)$ & $(0.118)$ & $(0.083)$ \\
\hline $\operatorname{Adj} . R^{2}$ & 0.029 & 0.073 & 0.109 & 0.081 & -0.009 \\
\hline
\end{tabular}

This table reports the slope coefficients, autocorrelation-robust standard errors in parentheses, and adjusted $R$-squared coefficients from regression: $V R P_{t, t+\tau}=\alpha+\beta^{\prime} X_{t, t+\tau}+\varepsilon_{t, t+\tau}$, where $V R P_{t, t+\tau}$ is the variance risk premium, computed as the difference between the ex-post realized variance at the end of the swap contract $(t+\tau)$ and the observed variance swap rate. Sample period goes from January 1996 to December 2006. In Panel A, equity risk is analyzed by including four variables in vector $X$ : the excess market return $\left(R_{W}-R_{f}\right)$, the size premium $(S M B)$, the value premium $(H M L)$, and the price-dividend ratio $(P D)$. In Panel $\mathrm{B}$, we analyze the relationship between the variance risk premium and three variables representing interest rates risk: innovations in the relative risk free rate $\left(R_{f} S T A T E\right)$, the slope of the yield curve $(T E R M)$ and a default premium $(D E F A U L T) . \mathrm{A}+$ sign denotes the residuals of the associated variable relative to the main source of risk: either market return in Panel A or the risk free rate in Panel B. The second $A d j . R^{2}$ line refers to the regression that includes only the main source of risk as explanatory variable. Panel $\mathrm{C}$ reports the business cycle risk coefficients corresponding to simple OLS regressions with consumption growth, employment growth, and an illiquidity measure, respectively, as the only independent variables. ${ }^{* * *}$ p-value $<0.01$; ** p-value $<0.05$; * p-value $<0.10$. 
Table 3

Different Measures of Risk and the Moments of the Equity Return Distribution

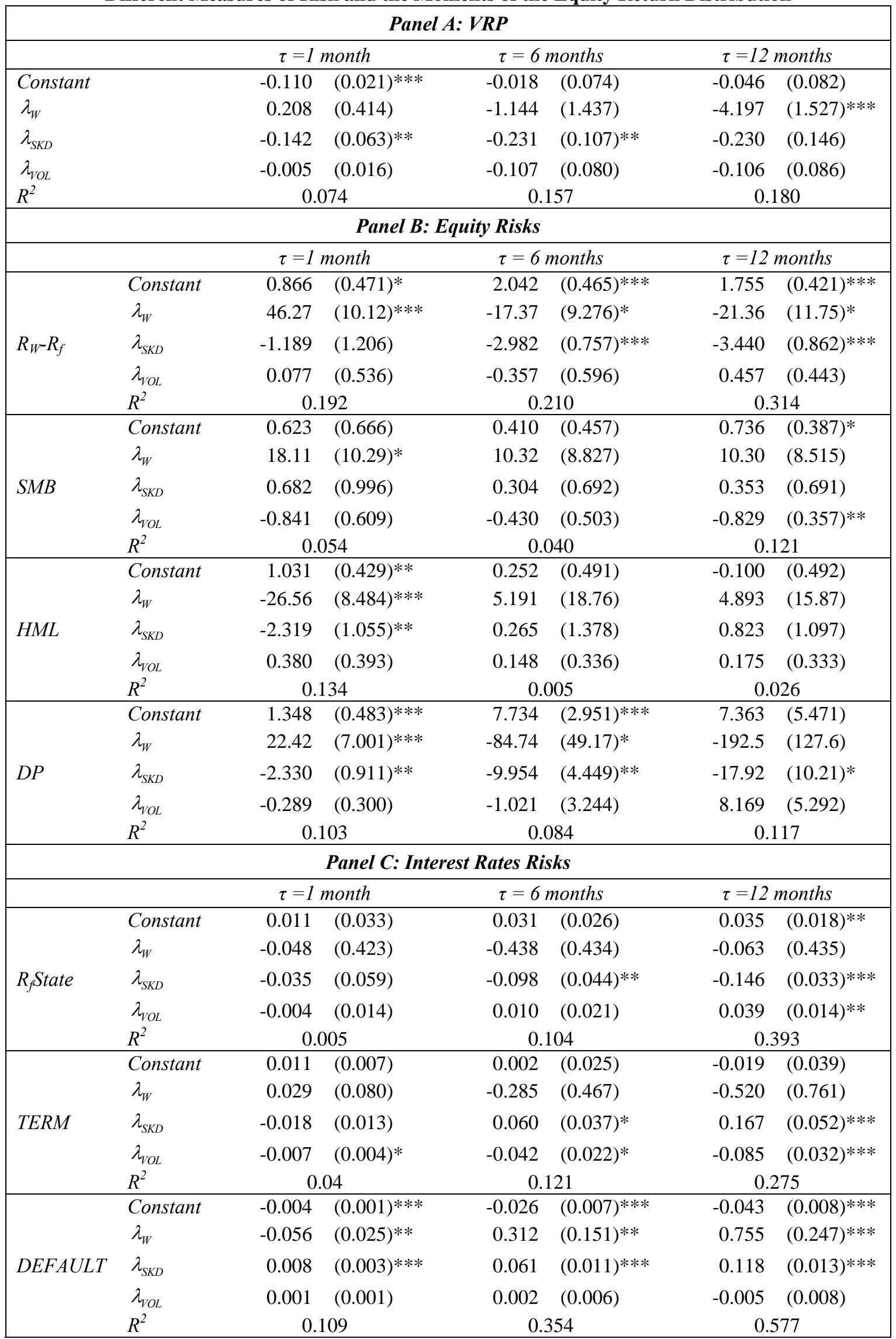


Table 3 (continuation)

Variance Risk and the Moments of the Equity Return Distribution

\begin{tabular}{|llrlrlll|}
\hline \multicolumn{7}{c|}{ Panel D: Business Cycle Risks } \\
\hline & Constant & 0.205 & $(0.031)^{* * *}$ & 0.193 & $(0.024)^{* * *}$ & 0.172 & $(0.025)^{* * *}$ \\
& $\lambda_{W}$ & 0.782 & $(0.690)$ & -0.403 & $(0.486)$ & 0.361 & $(0.551)$ \\
Consump. & $\lambda_{\text {SKD }}$ & -0.169 & $(0.089)^{*}$ & -0.088 & $(0.039)^{* *}$ & -0.053 & $(0.045)$ \\
Growth & $\lambda_{\text {VOL }}$ & 0.025 & $(0.022)$ & 0.019 & $(0.024)$ & 0.030 & $(0.026)$ \\
& $R^{2}$ & 0.05 & 0.079 & 0.083 \\
\hline Constant & 0.115 & $(0.022)^{* * *}$ & 0.148 & $(0.033)^{* * *}$ & 0.168 & $(0.032)^{* * *}$ \\
Employ. & $\lambda_{W}$ & -0.010 & $(0.257)$ & -0.809 & $(0.664)$ & -1.313 & $(0.924)$ \\
Growth & $\lambda_{\text {SKD }}$ & -0.076 & $(0.028)^{* *}$ & -0.207 & $(0.049)^{* * *}$ & -0.261 & $(0.064)^{* * *}$ \\
& $\lambda_{\text {VOL }}$ & 0.030 & $(0.018)^{*}$ & 0.070 & $(0.032)^{* *}$ & 0.083 & $(0.029)^{* * *}$ \\
& $R^{2}$ & 0.055 & 0.268 & 0.351 \\
\hline Aggregate & $\lambda_{W}$ & -5.945 & $(2.116)^{* * *}$ & -24.94 & $(7.772)^{* * *}$ & -44.61 & $(10.12)^{* * *}$ \\
Illiquidity & $\lambda_{\text {SKD }}$ & -4.638 & $(36.24)$ & 168.0 & $(166.8)$ & 218.0 & $(231.0)$ \\
Shocks & $\lambda_{\text {VOL }}$ & 15.01 & $(3.849)^{* * *}$ & 44.90 & $(12.41)^{* * *}$ & 74.33 & $(13.57)^{* * *}$ \\
& $R^{2}$ & 1.201 & $(1.571)$ & 5.440 & $(8.405)$ & 8.228 & $(9.065)$ \\
\end{tabular}

The table reports results from estimating the regression

$$
Y_{t, t+\tau}=\lambda_{0}+\lambda_{W}\left(\sigma_{W t, t+\tau} S_{W t, t+\tau}\right)+\lambda_{S K D}\left(\sigma_{W t, t+\tau}\left(K_{W t, t+\tau}-1\right)\right)+\lambda_{V O L} v_{W t, t+\tau}+\varepsilon_{t, t+\tau}, \tau=1,6,12
$$

Sample period goes from January 1996 to December 2006.The dependent variable $(Y)$ changes for each panel and each row. In panel A, the dependent variable is the Variance Risk Premium (VRP) computed as the difference between the ex-post realized variance at the end of the swap contract $(t+\tau)$ and the currently observed variance swap rate. In Panel $\mathrm{B}$, variables are related to equity market risk: the excess market return $\left(R_{W}-R_{f}\right)$, the size premium $(S M B)$, the value premium $(H M L)$, and the price-dividend ratio $(P D)$. In Panel C, variables based on interest rates are considered: the relative risk free rate $\left(R_{f} S T A T E\right)$, the slope of the yield curve (TERM), and a default premium (DEFAULT) computed as the difference between yields on Baa corporate bonds and government bonds. Panel $\mathrm{D}$ contains results regarding the aggregate consumption growth rate, the growth rate of employment, and an aggregate measure of illiquidity shocks. $\sigma_{W}, S_{W}$, and $K_{W}$ represent the standard deviation, skewness and kurtosis of the market return, respectively, and $v_{W t}=\operatorname{Cov}_{t}\left(\sigma_{W t+1}^{2}, R_{W t+1}^{2}\right) / \operatorname{Var}_{t}\left(\sigma_{W t+1}^{2}\right)$. All three moments are estimated with intra-daily data within the period corresponding to the swap maturity (1 month, 6 months or 12 months). Each row reports the coefficient estimates and their corresponding standard error in parenthesis. The last row displays the $R^{2}$ of the regression. ${ }^{* * *} \mathrm{p}$-value $<0.01$; ${ }^{* *} \mathrm{p}$-value $<0.05$; * $\mathrm{p}$-value $<0.10$. 
Table 4

Contribution of each Moment of the Return Distribution to the Explanation of the Variance Risk Premium and the State Variables

\begin{tabular}{|c|c|c|c|c|}
\hline & & $\tau=1$ month & $\tau=6$ months & $\tau=12$ months \\
\hline \multirow{4}{*}{$V R P$} & $\begin{array}{l}\lambda_{W}, \lambda_{S K D}, \lambda_{V O L} \\
\text { (unrestricted) }\end{array}$ & 0.074 & 0.157 & 0.180 \\
\hline & $\begin{array}{l}\lambda_{S K D}, \lambda_{V O L} \\
\text { (no skewness) }\end{array}$ & 0.071 & 0.144 & 0.062 \\
\hline & $\begin{array}{l}\lambda_{W}, \lambda_{\text {VOL }} \\
\text { (no kurtosis) }\end{array}$ & 0.004 & 0.081 & 0.110 \\
\hline & $\begin{array}{l}\lambda_{W}, \lambda_{S K D} \\
\text { (no volatility) }\end{array}$ & 0.073 & 0.113 & 0.145 \\
\hline \multirow{4}{*}{$R_{W}-R_{f}$} & $\lambda_{W}, \lambda_{S K D}, \lambda_{V O L}$ & 0.192 & 0.210 & 0.314 \\
\hline & $\lambda_{S K D}, \lambda_{V O L}$ & 0.004 & 0.170 & 0.253 \\
\hline & $\lambda_{W}, \lambda_{V O L}$ & 0.185 & 0.035 & 0.000 \\
\hline & $\lambda_{W}, \lambda_{S K D}$ & 0.191 & 0.203 & 0.301 \\
\hline \multirow{4}{*}{$P D$} & $\lambda_{W}, \lambda_{S K D}, \lambda_{V O L}$ & 0.103 & 0.084 & 0.117 \\
\hline & $\lambda_{S K D}, \lambda_{V O L}$ & 0.034 & 0.049 & 0.070 \\
\hline & $\lambda_{W}, \lambda_{V O L}$ & 0.063 & 0.012 & 0.036 \\
\hline & $\lambda_{W}, \lambda_{S K D}$ & 0.099 & 0.082 & 0.077 \\
\hline \multirow{4}{*}{$\begin{array}{l}\text { Consumption } \\
\text { Growth }\end{array}$} & $\lambda_{W}, \lambda_{S K D}, \lambda_{V O L}$ & 0.050 & 0.079 & 0.083 \\
\hline & $\lambda_{S K D}, \lambda_{V O L}$ & 0.035 & 0.069 & 0.061 \\
\hline & $\lambda_{W}, \lambda_{V O L}$ & 0.013 & 0.005 & 0.047 \\
\hline & $\lambda_{W}, \lambda_{S K D}$ & 0.044 & 0.070 & 0.055 \\
\hline \multirow{4}{*}{$\begin{array}{l}\text { Agg. Illiq. } \\
\text { Shocks }\end{array}$} & $\lambda_{W}, \lambda_{S K D}, \lambda_{V O L}$ & 0.092 & 0.212 & 0.350 \\
\hline & $\lambda_{S K D}, \lambda_{V O L}$ & 0.092 & 0.195 & 0.336 \\
\hline & $\lambda_{W}, \lambda_{V O L}$ & 0.011 & 0.056 & 0.087 \\
\hline & $\lambda_{W}, \lambda_{S K D}$ & 0.089 & 0.205 & 0.341 \\
\hline
\end{tabular}

The table reports $R^{2}$ statistics from the estimation of regression

$$
Y_{t, t+\tau}=\lambda_{0}+\lambda_{W}\left(\sigma_{W t, t+\tau} S_{W t, t+\tau}\right)+\lambda_{S K D}\left(\sigma_{W t, t+\tau}\left(K_{W t, t+\tau}-1\right)\right)+\lambda_{V O L} \nu_{W t, t+\tau}+\varepsilon_{t, t+\tau}, \tau=1,6,12
$$

Sample period goes from January 1996 to December 2006.The dependent variable $(Y)$, in the first column of the table is, alternatively, the variance risk premium $(V R P)$, the excess market return $\left(R_{W}-R_{f}\right)$, innovations in the price-dividend ratio $(P D)$, the aggregate non-durable consumption growth rate, and an aggregate measure of illiquidity shocks. For each group of results, the first row reports the $R$-squared of the full equation (considering the three explanatory variables). The following three rows report the $R$ squared of a regression including two out of the three explanatory variables, as indicated in the second column of the table. $\sigma_{W}, S_{W}$, and $K_{W}$ represent the standard deviation, skewness and kurtosis of the market return, respectively, and $v_{W t}=\operatorname{Cov}_{t}\left(\sigma_{W t+1}^{2}, R_{W t+1}^{2}\right) / \operatorname{Var}_{t}\left(\sigma_{W t+1}^{2}\right)$. All moments have been estimated with intra-daily data within the period corresponding to the swap maturity. 
Table 5

The Sources of the Variance Risk Premium with the Realized Variance Estimated from Daily Log-Returns

\begin{tabular}{|lrlrlrl|}
\hline & \multicolumn{2}{c}{$\tau=1$ month } & \multicolumn{2}{c|}{$\tau=6$ months } & \multicolumn{2}{c|}{$\tau=12$ months } \\
\hline Constant & -0.081 & $(0.022)^{* * *}$ & -0.056 & $(0.066)$ & -0.119 & $(0.065)^{*}$ \\
$\lambda_{W}$ & 1.001 & $(0.902)$ & 0.448 & $(1.418)$ & -0.502 & $(1.903)$ \\
$\lambda_{S K D}$ & -0.557 & $(0.324)^{*}$ & -0.632 & $(0.272)^{* *}$ & -1.073 & $(0.320)^{* * *}$ \\
$\lambda_{\text {VOL }}$ & 0.018 & $(0.039)$ & -0.007 & $(0.072)$ & 0.154 & $(0.102)$ \\
$R^{2}$ & \multicolumn{2}{c}{0.082} & \multicolumn{2}{c}{0.162} & 0.202 \\
\hline
\end{tabular}

This table reports results from the estimation of regression

$$
V R P_{t, t+\tau}=\lambda_{0}+\lambda_{W}\left(\sigma_{W t, t+\tau} S_{W t, t+\tau}\right)+\lambda_{S K D}\left(\sigma_{W t, t+\tau}\left(K_{W t, t+\tau}-1\right)\right)+\lambda_{V O L} \nu_{W t, t+\tau}+\varepsilon_{t, t+\tau}, \tau=1,6,12
$$

where $V R P_{t, t+\tau}$ is the Variance Risk Premium computed as the difference between the ex-post realized variance at maturity of the swap contract $(t+\tau)$ and the observed variance swap rate. $\sigma_{W}, S_{W}$, and $K_{W}$ represent the standard deviation, the skewness and the kurtosis of the market return, respectively, and $v_{W t}=\operatorname{Cov}_{t}\left(\sigma_{W t+1}^{2}, R_{W t+1}^{2}\right) / \operatorname{Var}_{t}\left(\sigma_{W t+1}^{2}\right)$. All three moments are estimated with daily data within the period corresponding to the swap maturity (1 month, 6 months or 12 months). Sample period goes from January 1996 to December 2006. Each row reports the estimates and their corresponding standard error in parentheses. The last row displays the $R^{2}$ of the regression. ${ }^{* * *} \mathrm{p}$-value $<0.01$; ${ }^{* *} \mathrm{p}$-value $<0.05$; ${ }^{*} \mathrm{p}$ value $<0.10$. 
Table 6

Hedging and Non-Normality of the Variance Swap Premium

Sample Period 1990-2012, $\tau=1$ month

\begin{tabular}{|c|c|c|c|c|c|}
\hline \multicolumn{6}{|c|}{ Panel A: Short-term Hedging Ability of the Variance Swap Contract } \\
\hline \multicolumn{2}{|c|}{ Equity Risks } & \multicolumn{2}{|c|}{ Interest Rate Risks } & \multicolumn{2}{|c|}{ Business Cycle Risks } \\
\hline$R_{W}-R_{f}$ & $\begin{array}{c}-3.184^{* * *} \\
(1.039)\end{array}$ & $R_{f}$ State & $\begin{array}{c}26.456 \\
(18.419)\end{array}$ & $\begin{array}{l}\text { Consumption } \\
\text { Growth }\end{array}$ & $\begin{array}{l}-3.349 \\
(8.552)\end{array}$ \\
\hline \multirow[t]{2}{*}{$S M B^{+}$} & \multirow{2}{*}{$\begin{array}{c}-0.304 \\
(0.444)\end{array}$} & \multirow[t]{2}{*}{ TERM ${ }^{+}$} & \multirow{2}{*}{$\begin{array}{c}-17.586 \\
(16.747)\end{array}$} & Adj. $R^{2}$ & -0.003 \\
\hline & & & & Employment & 20.017 \\
\hline \multirow[t]{2}{*}{$H M L^{+}$} & \multirow{2}{*}{$\begin{array}{c}-0.291 \\
(0.632)\end{array}$} & \multirow[t]{3}{*}{ DEFAULT $T^{+}$} & \multirow{3}{*}{$\begin{array}{c}62.854 \\
(64.394)\end{array}$} & Growth & $(24.333)$ \\
\hline & & & & Adj. $R^{2}$ & 0.009 \\
\hline$P D^{+}$ & $\begin{array}{l}-0.019 \\
(0.076)\end{array}$ & & & $\begin{array}{l}\text { Agg. Illiq. } \\
\text { Shocks }\end{array}$ & $\begin{array}{c}0.509 \\
(0.469)\end{array}$ \\
\hline $\operatorname{Adj} . R^{2}$ & 0.196 & $\operatorname{Adj} . R^{2}$ & 0.037 & Adj. $R^{2}$ & 0.006 \\
\hline $\operatorname{Adj} . R^{2}\left(R_{W}\right)$ & 0.203 & $\operatorname{Adj} . R^{2}\left(R_{f}\right)$ & 0.027 & & \\
\hline \multicolumn{6}{|c|}{ Panel B: Sources of the Variance Risk Premium } \\
\hline Constant & \multicolumn{2}{|c|}{$\lambda_{W}$} & & $\lambda_{V O L}$ & $R^{2}$ \\
\hline$-0.122 * * *$ & \multicolumn{2}{|c|}{$0.682 *$} & & -0.004 & 0.103 \\
\hline 0.022 & \multicolumn{2}{|c|}{$(0.371)$} & & $(0.014)$ & \\
\hline
\end{tabular}

For description of the analysis shown in Panel A, see notes in Table 2. For description of the analysis shown in Panel B, see notes in Table 3. The exception is the variance risk premium that is now computed using data on realized and implied volatility provided by Hao Zhou in his web site. *** p-value $<0.01$; ** p-value $<0.05 ;$ * p-value $<0.10$. 
Table 7

Out-of-sample Portfolio Performance with and without Variance Swaps

\begin{tabular}{|c|c|c|c|c|c|c|c|c|}
\hline & \multicolumn{2}{|c|}{$\begin{array}{l}\tau=1 \text { month } \\
1996-2006\end{array}$} & \multicolumn{2}{|c|}{$\begin{array}{l}\tau=6 \text { month } \\
1996-2006\end{array}$} & \multicolumn{2}{|c|}{$\begin{array}{c}\tau=12 \text { months } \\
1996-2006\end{array}$} & \multicolumn{2}{|c|}{$\begin{array}{c}\tau=1 \text { months } \\
\text { Zhou Data } \\
1990-2012\end{array}$} \\
\hline & $R_{W}$ & $R_{W}+V R P$ & $R_{W}$ & $R_{W}+V R P$ & $R_{W}$ & $R_{W}+V R P$ & $R_{W}$ & $R_{W}+V R P$ \\
\hline Mean & 0.004 & -0.009 & 0.015 & -0.008 & 0.026 & -0.010 & 0.008 & -0.009 \\
\hline Min & -0.102 & -0.129 & -0.276 & -0.207 & -0.297 & -0.212 & -0.172 & -0.116 \\
\hline $\operatorname{Max}$ & 0.083 & 0.051 & 0.239 & 0.108 & 0.427 & 0.127 & 0.113 & 0.107 \\
\hline$S D$ & 0.041 & 0.030 & 0.109 & 0.062 & 0.176 & 0.082 & 0.047 & 0.023 \\
\hline Skewness & -0.507 & -1.255 & -0.422 & -0.732 & 0.005 & -0.783 & -0.726 & -0.821 \\
\hline Excess Kurtosis & 0.269 & 2.655 & -0.179 & 0.228 & -0.786 & -0.159 & 0.918 & 6.049 \\
\hline Modified VaR & 0.106 & 0.109 & 0.260 & 0.177 & 0.350 & 0.227 & 0.126 & 0.105 \\
\hline \multicolumn{9}{|c|}{$\begin{array}{l}\text { Distribution of the Difference in the Modified Value-at-Risk } \\
\qquad\left(\operatorname{Mod} \operatorname{VaR}_{R W}-\operatorname{Mod} \operatorname{VaR} R_{R W+V R P}\right)\end{array}$} \\
\hline $\begin{array}{l}\text { Median } \\
95 \% C I \\
\operatorname{Pr}(x<0)\end{array}$ & \multicolumn{2}{|c|}{$\begin{array}{c}0.016 \\
(-0.024,0.051) \\
13.6 \%\end{array}$} & \multicolumn{2}{|c|}{$\begin{array}{c}0.043 \\
(-0.049,0.111) \\
12.5 \%\end{array}$} & \multicolumn{2}{|c|}{$\begin{array}{c}0.076 \\
(-0.037,0.148) \\
6.3 \%\end{array}$} & \multicolumn{2}{|c|}{$\begin{array}{c}0.061 \\
(0.028,0.317) \\
0.1 \%\end{array}$} \\
\hline
\end{tabular}

Each panel provides the statistics indicated in the first column for the returns on two investment strategies: a $100 \%$ investment in the equity market portfolio $\left(R_{W}\right)$ and a portfolio that combines the equity market and the variance swap $\left(R_{W}+V R P\right)$. Portfolio weights for the latter are estimated each month using a recursive process that employs five years of previous data to minimize the modified Value-at-Risk of the resulting portfolio. The last panel to the right employs an extended sample period using data provided by Hao Zhou in his web site. The modified VaR of the two portfolios are compared by a bootstrap procedure with the results shown in the last row of the table. This row provides the median, the $2.5 \%$ and $97.5 \%$ percentiles, and the cumulative density of negative values for the difference between the modified $\operatorname{VaR}$ of the two portfolios. 
Figure 1

Variance Swap Rate and Realized Variance for Different Maturities
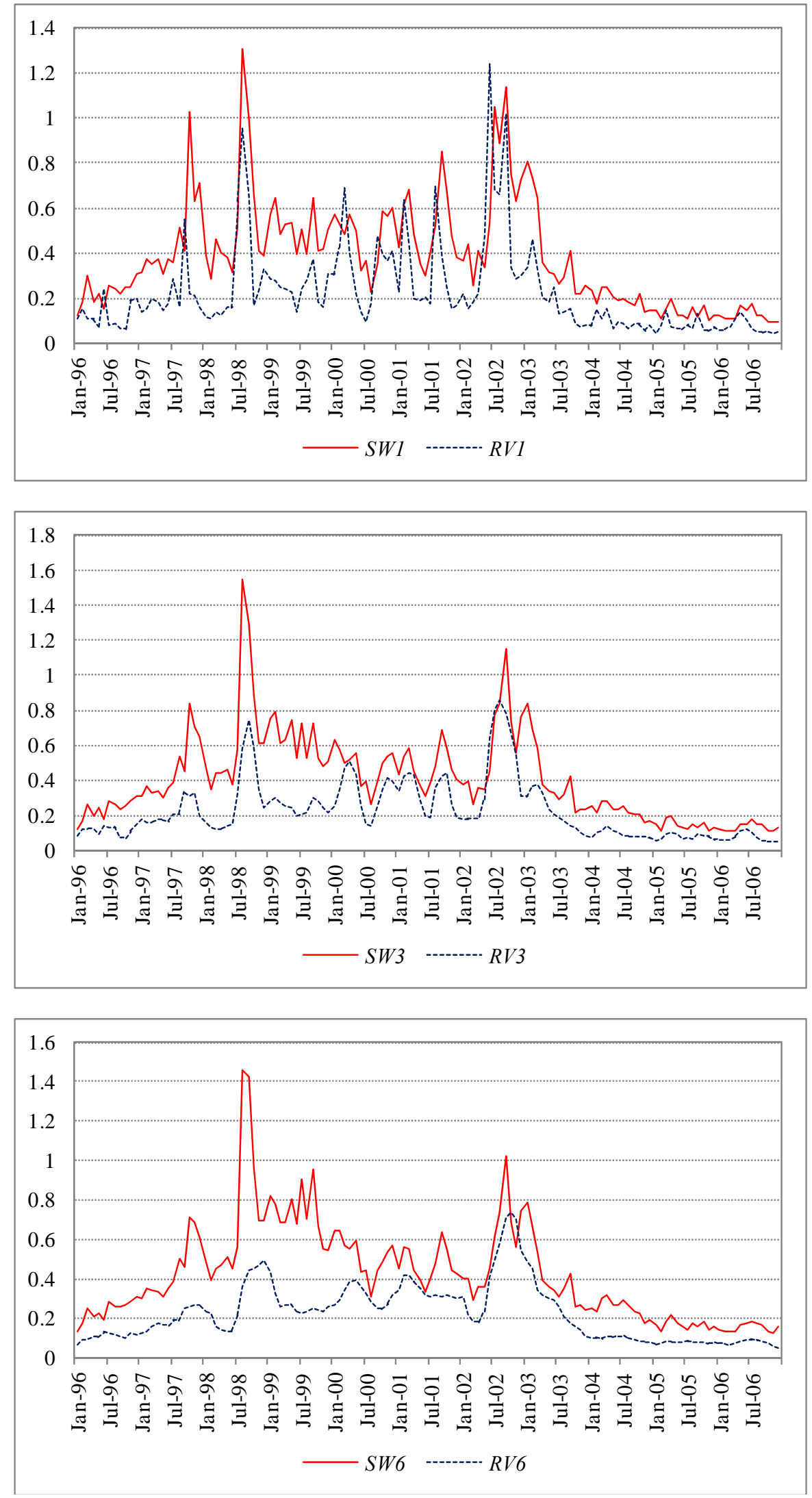
Figure 2

Illiquidity and Default Risks: Actual versus Fitted Values from Regressions on Non-normal Determinants of the Variance Risk Premium, at the 12-Month Horizon
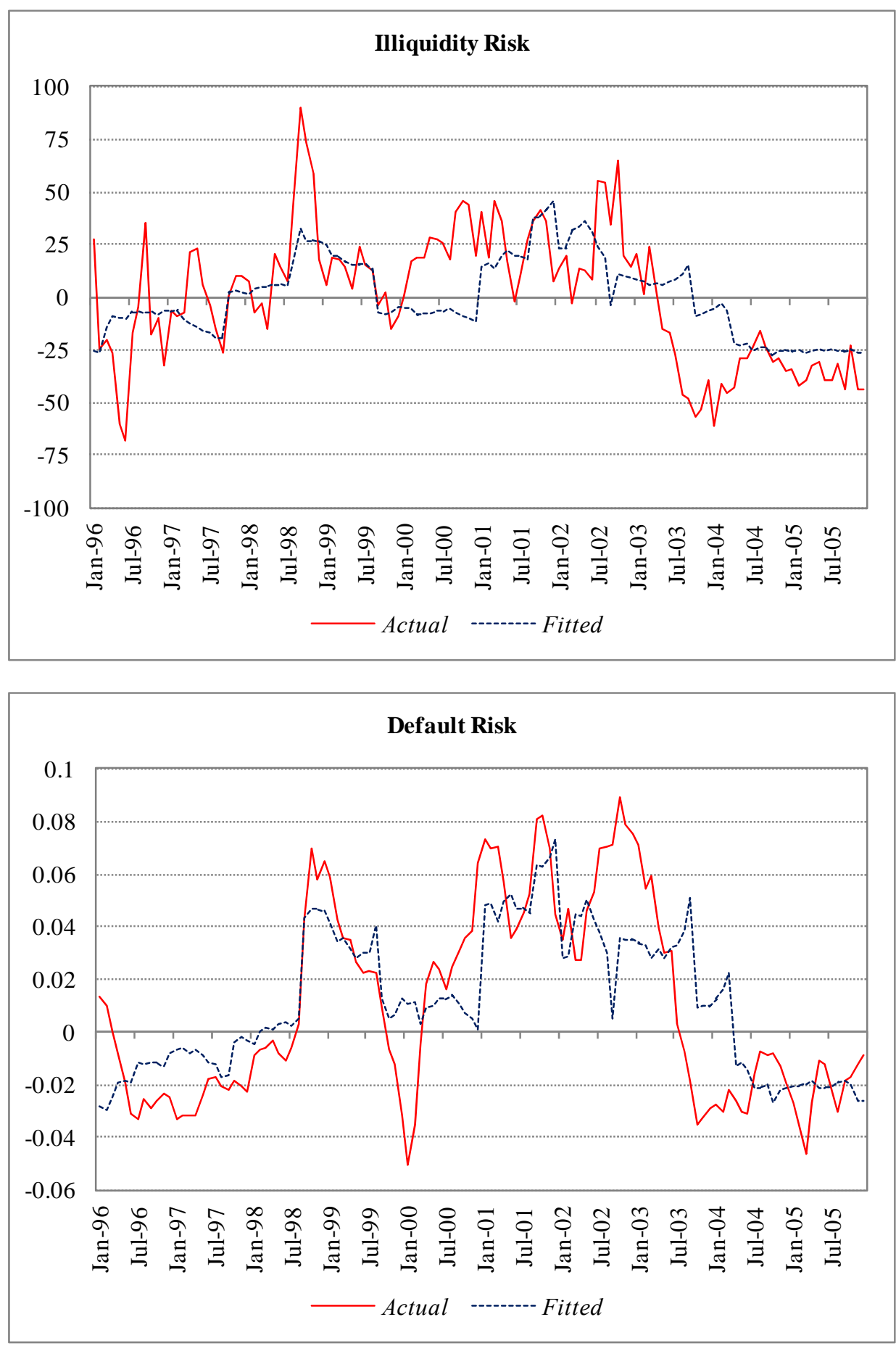
Figure 3

Variance Risk Premium using either Realized Variance Estimated from Intra-day Returns or from Daily Returns
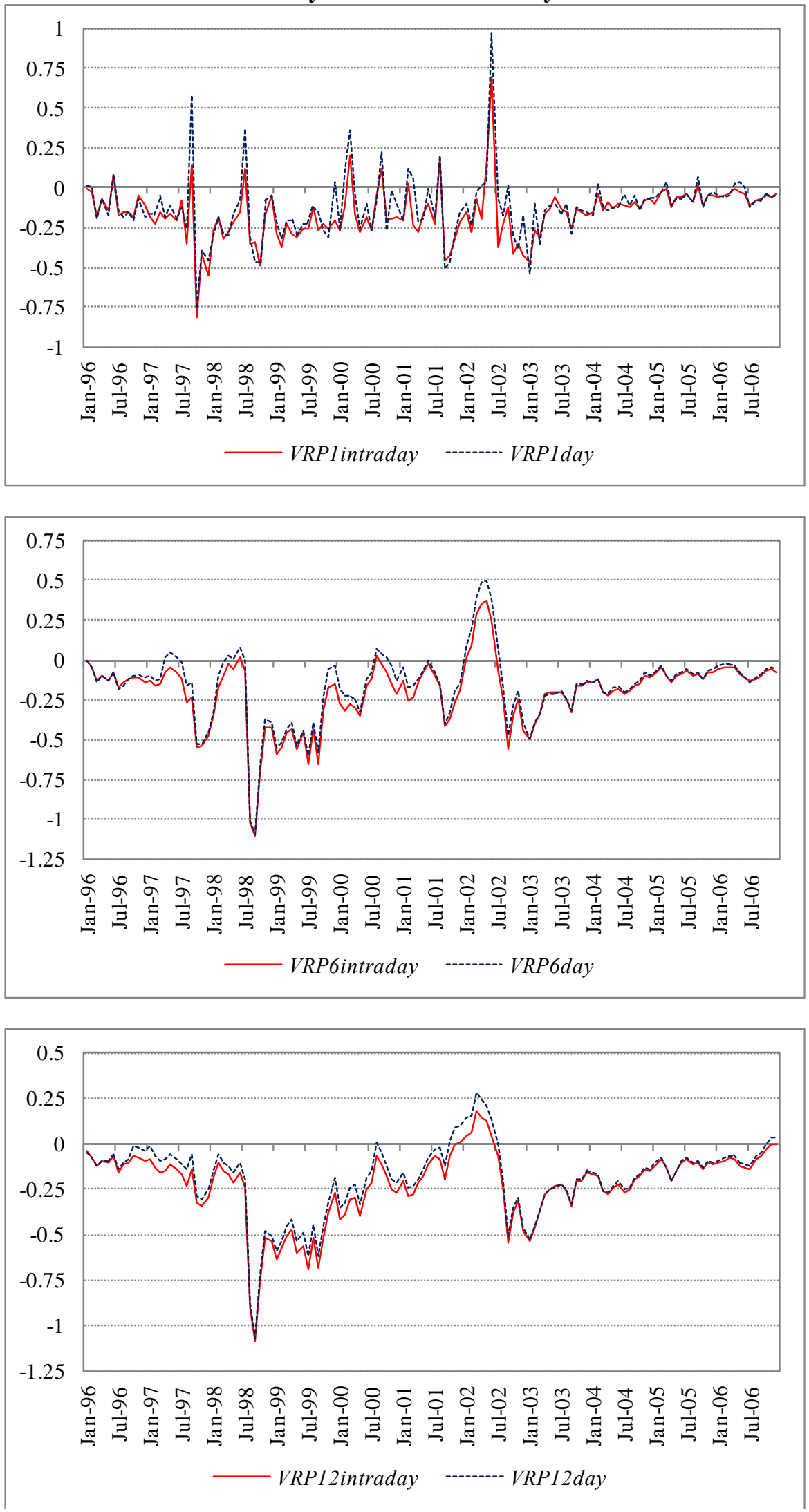
Figure 4

Comparing the One-month Variance Swap Rates and VIX

Histogram and Descriptive Statistics, January 1996 to December 2006

One-month Swap Rates

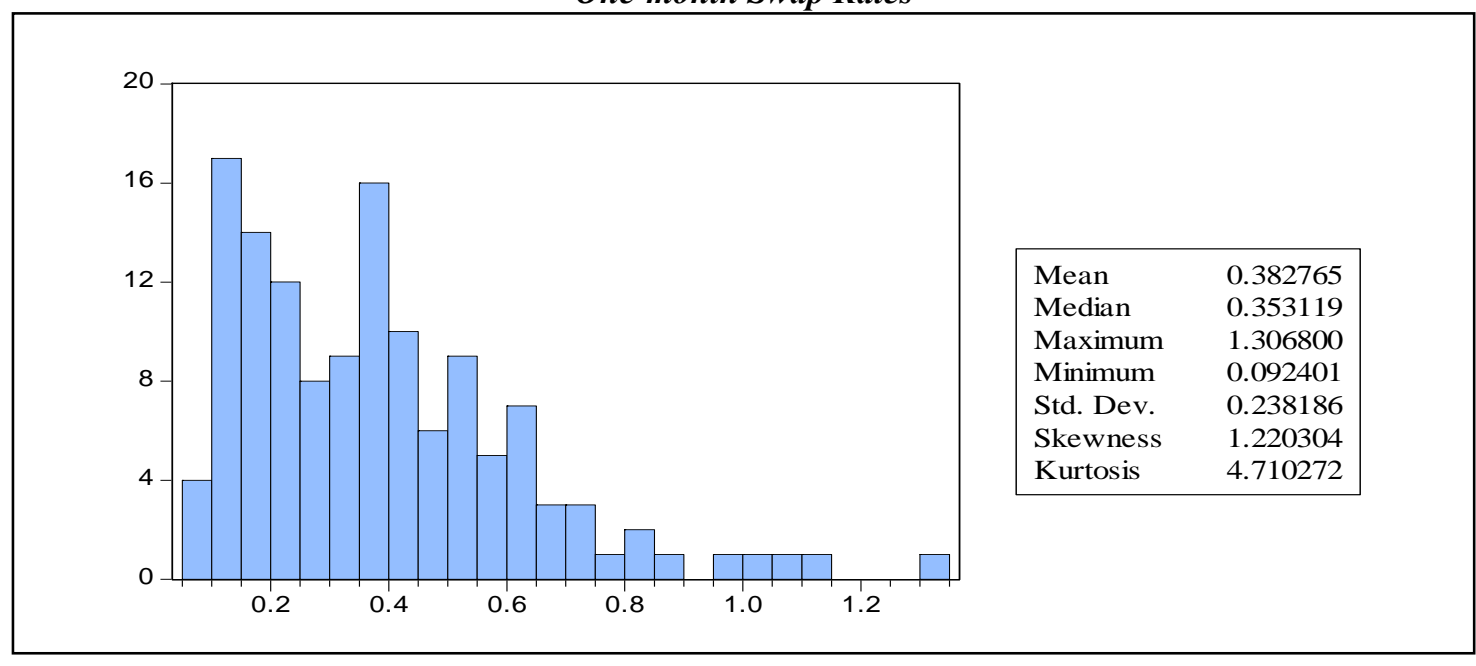

VIX

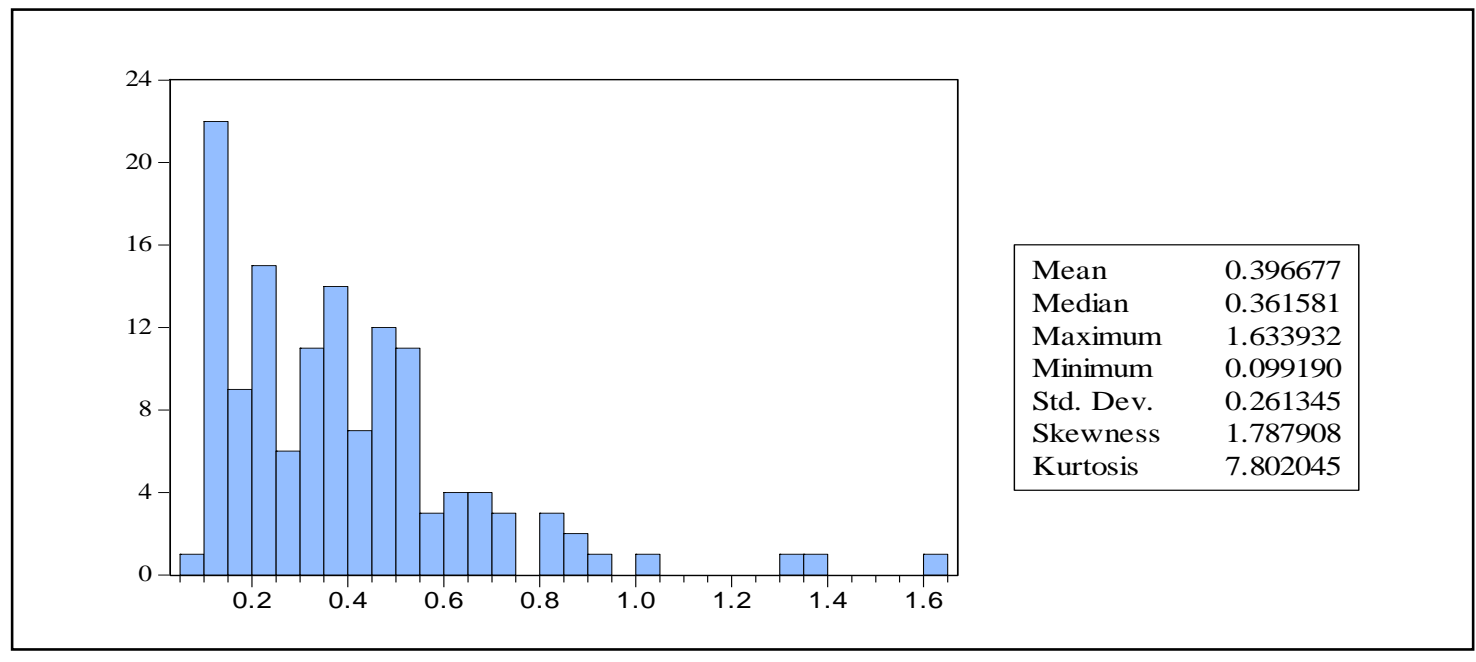


Figure 5

Variance Risk Premium using either one-month Variance Swap Rates (1996-2006) or VIX (1990-2012)
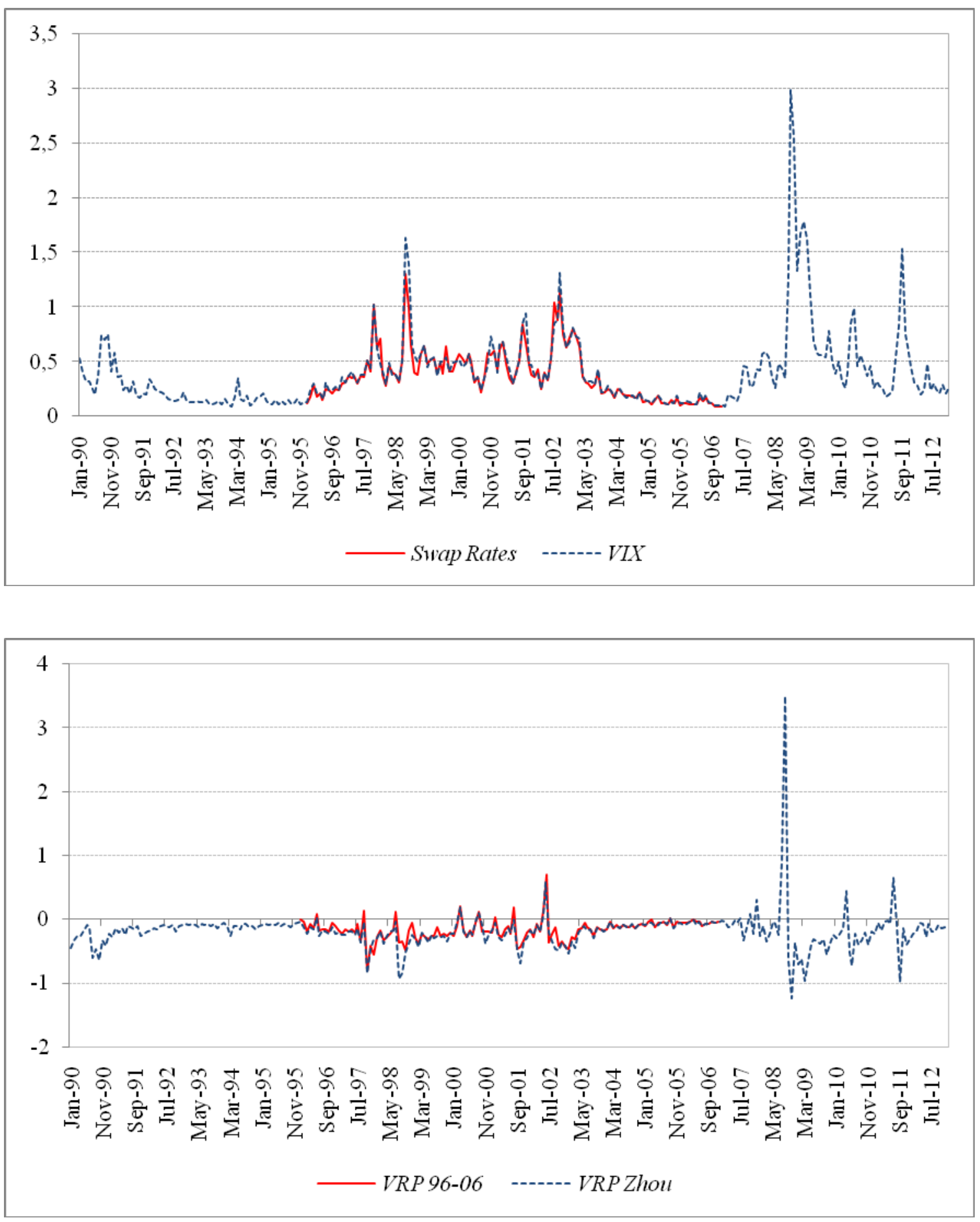
Figure 6

Optimal Monthly Weights for the Equity Market Portfolio and the Variance Swap when Minimising the Modified Value-at-Risk

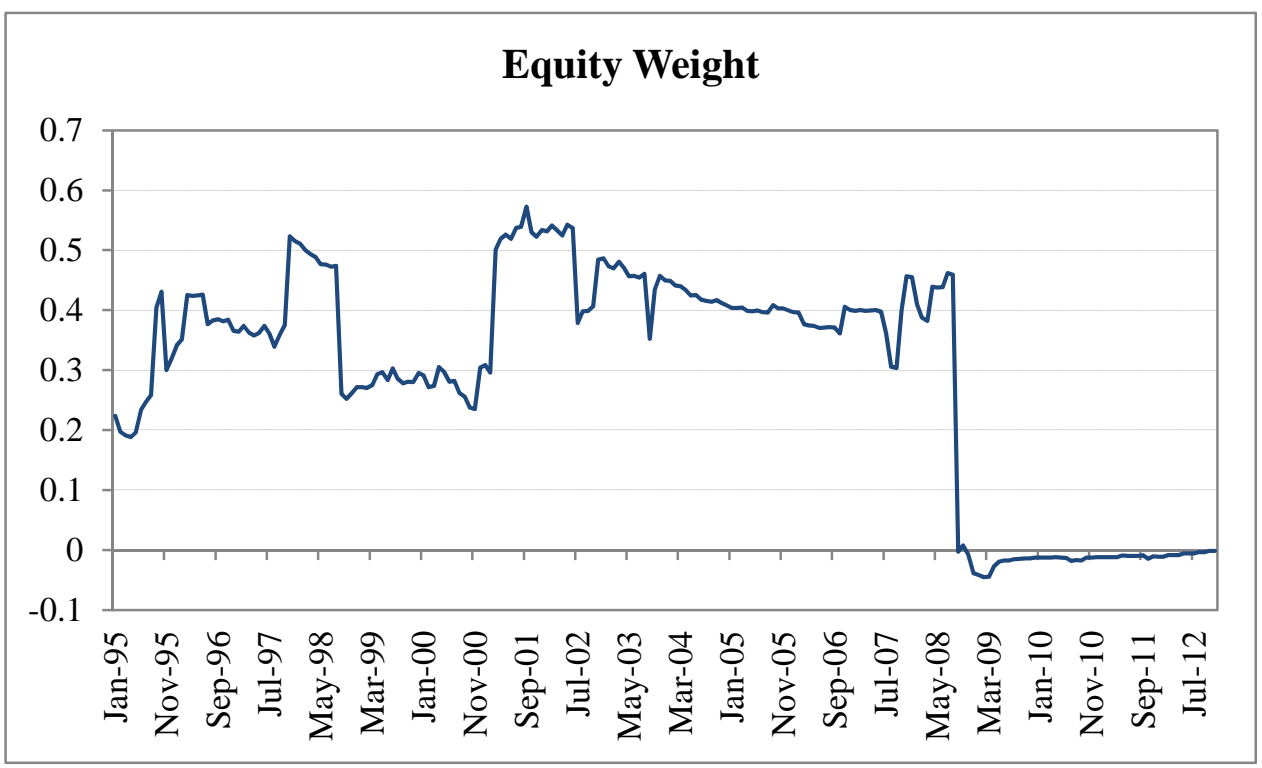

